\title{
A combined electrochemical and theoretical study of pyridine-based Schiff bases as novel corrosion inhibitors for mild steel in hydrochloric acid medium
}

\author{
PARUL DOHARE $^{\mathrm{a}}, \mathrm{M} \mathrm{A} \mathrm{QURAISHI}^{\mathrm{b}, *}$ and I B OBOT ${ }^{\mathrm{b}}$ \\ ${ }^{a}$ Department of Chemistry, Indian Institute of Technology, Banaras Hindu University, Varanasi, \\ Uttar Pradesh 221 005, India \\ ${ }^{\mathrm{b}}$ Center of Research Excellence in Corrosion, Research Institute, King Fahd University of Petroleum \\ and Minerals, Dhahran 31261, Saudi Arabia \\ E-mail: maquraishi.apc@itbhu.ac.in; mumtaz.quraishi@kfupm.edu.sa
}

MS received 21 June 2017; revised 13 November 2017; accepted 19 November 2017; published online 1 February 2018

\begin{abstract}
Three pyridine-based Schiff bases namely $\mathrm{N}^{2}, \mathrm{~N}^{6}$-bis(4-methylbenzylidene)pyridine-2,6-diamine (DAP-1), $\mathrm{N}^{2}, \mathrm{~N}^{6}$-dibenzylidenepyridine-2,6-diamine (DAP-2) and $\mathrm{N}^{2}, \mathrm{~N}^{6}$-bis(4-nitrobenzylidene)pyridine-2,6diamine (DAP-3) were synthesized, characterized, and their corrosion inhibition performance was studied on mild steel (MS) in $1 \mathrm{M}$ hydrochloric acid solution using electrochemical experiments and theoretical study. The results showed that all the three DAPs act as mixed type corrosion inhibitors, and are adsorbed on MS surface by following Langmuir adsorption isotherm. The methyl-substituted DAP-1 showed maximum inhibition effiency of $98.5 \%$ at $40 \mathrm{mgL}^{-1}$. The formation of inhibitor film on MS surface was confirmed by SEM and AFM. Quantum chemical calculations and Monte Carlo simulations were used to understand metal-inhibitor interaction and orientation of adsorption of DAP molecules. A good correlation was observed between theoretical and experimental results.
\end{abstract}

Keywords. Schiff base; EIS; AFM; SEM; DFT; Monte Carlo (MC) simulation.

\section{Introduction}

Mild steel finds wide application in different industries like petroleum refineries, storage tanks, power plants, etc., due to its low cost and high strength. However, it undergoes corrosion in contact with hydrochloric acid, during pickling and de-rusting, industrial cleaning, and acidizing. Therefore, inhibitors are usually added in acid solution to prevent metal dissolution. ${ }^{1-3}$ The corrosion inhibition efficiencies of various organic compounds on the corrosion of steel have been investigated experimentally. ${ }^{4-8}$ The inhibition action of organic compounds related to molecular parameters of inhibitors include the presence of lone pair of electrons pi bonds of aromatic ring, planarity, steric factors, and energy gap between HOMO and LUMO. ${ }^{9-15}$ Schiff bases (SB) are the reaction products of amine and carbonyl compounds and act as a potential class of corrosion inhibitors. ${ }^{16}$ These compounds have wide applications in biological, clinical and

\footnotetext{
*For correspondence
}

industrial fields as corrosion inhibitors, catalysts, dyes, pigments, etc. ${ }^{17-19}$

Survey of the literature reveals that SBs act as efficient corrosion inhibitors for various metals in acidic solution. Negm et al., ${ }^{20}$ studied the corrosion inhibition behavior of four Schiff bases of the amine as corrosion inhibitors on mild steel in $1 \mathrm{M} \mathrm{HCl}$ solution. These authors have reported 60-90\% inhibition efficiency (IE) at $400 \mathrm{mgL}^{-1}$. Sorkhabi et al., ${ }^{21}$ investigated Schiff bases derived from 2-aminopyridine as corrosion inhibitors. These compounds exhibited a maximum IE of 85$95 \%$ at $200 \mathrm{mgL}^{-1}$. Yan Ji et al., ${ }^{22}$ reported corrosion inhibition action of Schiff base derived from pyridin-2ylmethyl-N,N-diethylaniline (BPMA) that showed corrosion inhibition efficiency $88.1 \%$ at $450 \mathrm{ppm}$. Hegazy et al. ${ }^{23}$ derived Schiff bases from benzylidene thiourea that gave 80-90\% inhibition efficiency at very high concentration range $\left(150 \mathrm{mgL}^{-1}\right)$. The inhibition efficiency of Schiff bases has prompted us to synthesize new Schiff bases to study their corrosion inhibition behavior. In the present investigation, we have synthesized three Schiff

Electronic supplementary material: The online version of this article (https://doi.org/10.1007/s12039-017-1408-x) contains supplementary material, which is available to authorized users. 
base derived from 2,6-diaminopyridine, namely, $\mathrm{N}^{2}, \mathrm{~N}^{6}$ bis(4-methylbenzylidene)pyridine-2,6-diamine (DAP1), $\mathrm{N}^{2}, \mathrm{~N}^{6}$-dibenzylidenepyridine-2,6-diamine (DAP -2) and $\mathrm{N}^{2}, \mathrm{~N}^{6}$-bis(4-nitrobenzylidene)pyridine-2,6diamine (DAP-3) and studied corrosion inhibition for mild steel corrosion in $1 \mathrm{M} \mathrm{HCl}$ medium. The survey of literature showed that these SBs have shown biological activities as anti-cancer, anti-viral, anti-microbial, etc., agents. ${ }^{24-26}$ In addition to this, these molecules are likely to give good inhibition efficiency as they have nitrogen containing pyridine nucleus, two $(\mathrm{CH}=\mathrm{N})$ azomethine group and two substituted phenyl groups in the same molecule. These structural features favor adsorption of molecules on the metal surface. The corrosion inhibition tests were performed on mild steel in acidic medium using potentiodynamic polarization, electrochemical impedance spectroscopy, gravimetry, surface SEM by scanning electron microscopy (SEM) and atomic force microscopy (AFM). The theoretical calculations using density functional theory (DFT) and the Monte Carlo simulation were also used to establish a correlation between molecular structures and IE.

\section{Experimental}

\subsection{Materials}

The synthesis of Schiff bases is reported in literature ${ }^{27}$ and the scheme for their synthesis is shown in Figure 1. A mixture of 2,6-diaminopyridine $(1.0 \mathrm{mmol})$ and various substituted aromatic aldehydes were taken in round-bottom flask. $50 \mathrm{~mL}$ of ethanol was added to the reaction mixture and refluxed approximately $3-5 \mathrm{~h}$. The obtained solid mass was recrystallized from ethanol. The chemicals used for this synthesis were obtained from Merck and SD Fine, India. The molecular structures, analytical data and abbreviations of the inhibitors are given in Table 1. The NMR spectra of DAPs are given in Supplementary Information (SI) as Figures S1-S3. The mild steel used for the weight loss, surface analysis and electrochemical experiments had the following composition; (wt\%): $\mathrm{C}=0.076, \mathrm{Mn}=0.192, \mathrm{P}=0.012, \mathrm{Si}=0.026$, $\mathrm{Cr}=0.050, \mathrm{Al}=0.023$ and remaining Fe. Before performing the experiments, the mild steel specimens were abraded with different grades of emery paper (600, 800 and 1200), washed with the double distilled water, and degreased with the ethyl alcohol. The test solution used for the experiment was prepared by dilution of the analytical grade $\mathrm{HCl}(37 \%)$ with double distilled water.

\subsection{Measurements}

2.2a Gravimetric Measurements: For gravimetric measurements, the MS specimen was cut into size of $2.5 \times$ $2 \times 0.025 \mathrm{~cm}^{3}$. Gravimetric experiments were performed according to ASTM standard method. ${ }^{28}$ The corrosion rates $C_{\mathrm{R}}\left(\mathrm{mg} \mathrm{cm}^{-2} \mathrm{~h}^{-1}\right)$ were calculated using following equation:

$C_{\mathrm{R}}=\frac{W}{A t}$

Here, $W=$ weight of MS coupon, $A=$ total area and $\mathrm{t}$ is the exposure time $(3 \mathrm{~h})$. With the calculated corrosion rate, the inhibition efficiency $\eta \%$ was calculated as follows: ${ }^{29}$

$\eta \%=\frac{C_{\mathrm{R}}-C_{\mathrm{R}(\mathrm{i})}}{C_{\mathrm{R}}} \times 100$

The surface coverage $(\theta)$ was calculated using the following equation:

$\theta=\frac{C_{\mathrm{R}}-C_{\mathrm{R}(\mathrm{i})}}{C_{\mathrm{R}}}$

Where, $C_{\mathrm{R}}$ and $C_{\mathrm{R}(\mathrm{i})}$ are the corrosion rates in the absence and presence of inhibitor, respectively.

2.2b Electrochemical studies: Electrochemical impedance (EIS) measurements and potentio-dynamic polarization studies were carried out using Echem Analyst (5.50 V) software. All electrochemical experiments were performed in a Gamery three electrodes electrochemical cell with MS as working electrode, platinum as the counter electrode and saturated calomel electrode (SCE) as the reference electrode. The working electrode with the exposed surface of $1.0 \mathrm{~cm}^{2}$ was immersed into the aggressive solutions with and without inhibitor, and then the open circuit potential was measured

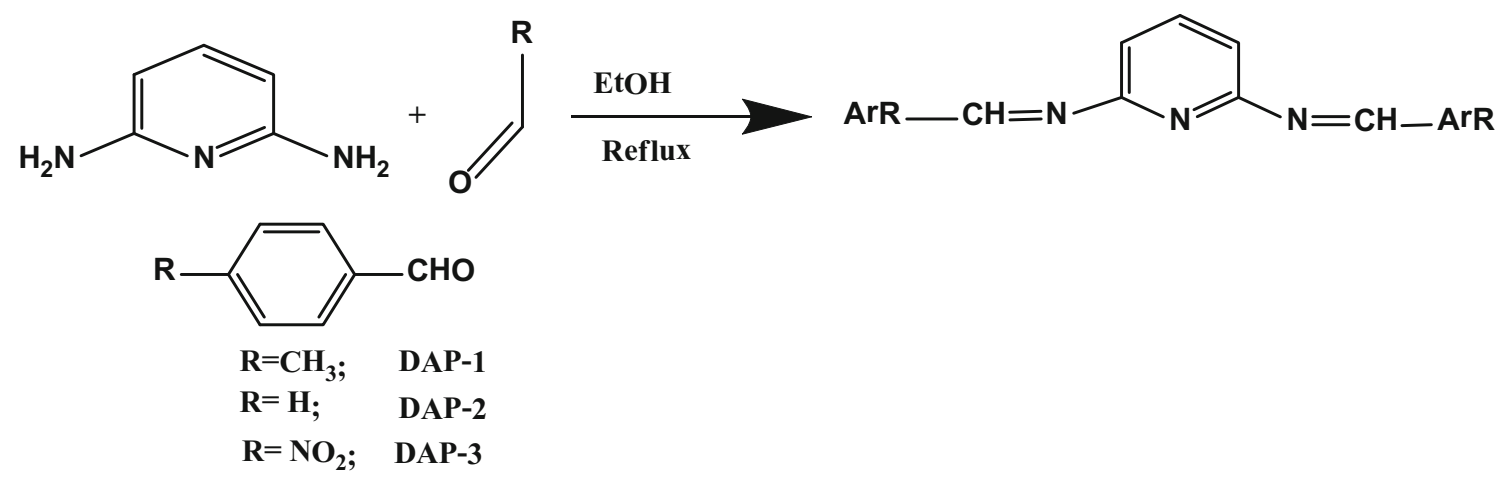

Figure 1. Synthetic route of studied inhibitor molecules, DAPs. 


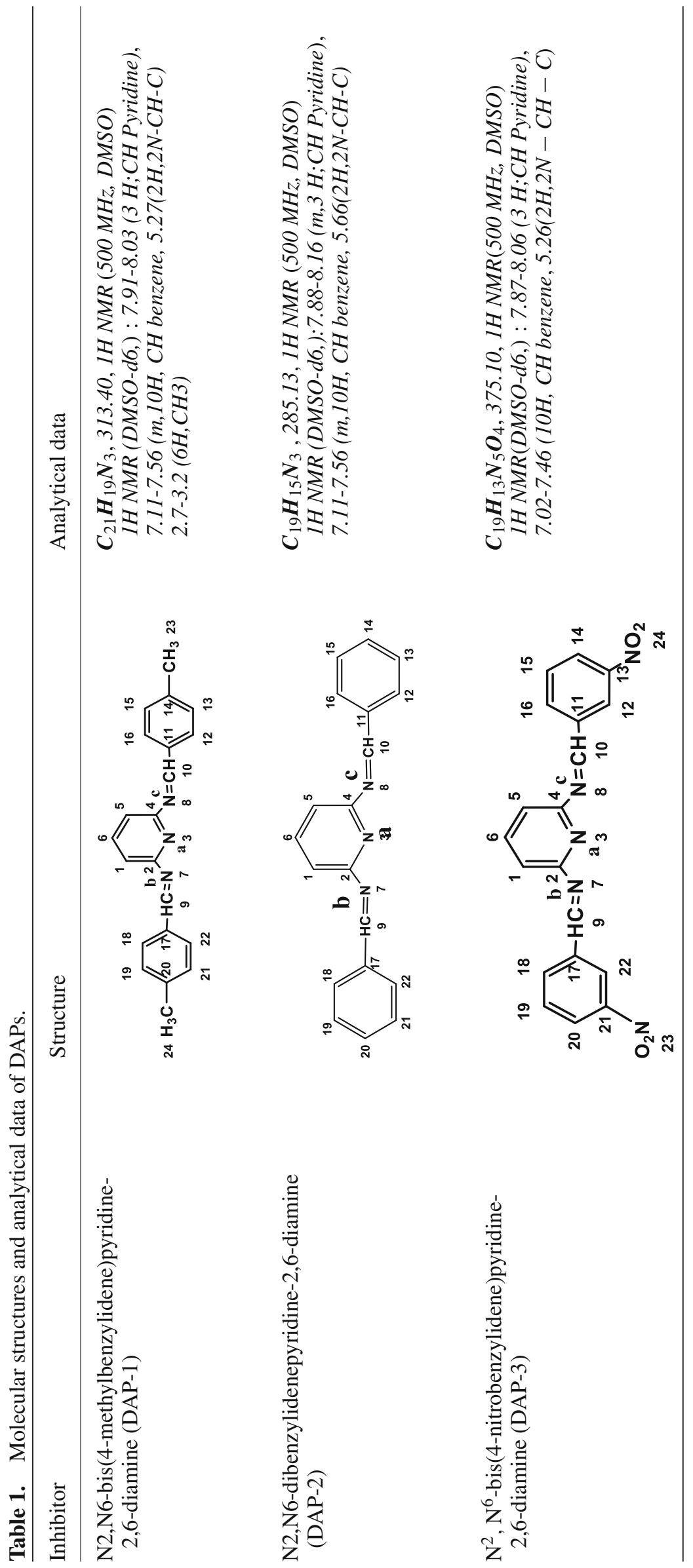


after $30 \mathrm{~min}$. EIS measurements were performed at corrosion potentials $\left(E_{\text {corr }}\right)$, over a frequency range of $100 \mathrm{kHz}$ to $10 \mathrm{mHz}$ with an AC signal amplitude perturbation of 10 $\mathrm{mV}$ peak to peak. Potentio-dynamic polarization studies were performed with a scan rate of $1 \mathrm{mVs}^{-1}$ in the potential range from $-250 \mathrm{mV}$ to $+250 \mathrm{mV}$. All potentials were recorded with respect to the SCE.

2.2c Surface analysis: The MS coupon was cut into an appropriate dimension of $2.5 \times 2 \times 0.025 \mathrm{~cm}^{3}$, and then immersed into the $1 \mathrm{M} \mathrm{HCl}$ solution in the absence and presence of inhibitors having optimum concentration $40 \mathrm{mgL}^{-1}$ for $3 \mathrm{~h}$. The strip was then taken out and washed with distilled water, degreased with acetone, dried at ambient temperature, and mechanically cut into $1.0 \mathrm{~cm}^{2}$ size for SEM investigations. SEM study was carried out at an accelerating voltage of $5.0 \mathrm{kV}$ and $5.0 \mathrm{~K} \times$ magnification by using a Zeiss EVO 50 XVP instrument (Germany). AFM study was done using NT-MDT multimode (Russia) controlled by a solver scanning probe microscope controller.

2.2d Quantumchemical calculations: Quantumchemical calculations were performed using density functional theory (DFT) with the Becke's three parameter exchange functional along with the Lee-Yang-Parr non-local correlation functional (B3LYP) with $6-31+\mathrm{G}(\mathrm{d}, \mathrm{p})$ basis set using Gaussian 09 program. ${ }^{30,31}$ The theoretical parameters obtained were $E_{\mathrm{HOMO}}, E_{\mathrm{LUMO}}, \Delta E\left(E_{\mathrm{LUMO}}-E_{\mathrm{HOMO}}\right)$, Mullikan charge on heteroatoms $(\mathrm{N}, \mathrm{O})$, and dipole moment $(\mu)$. Some other important parameters calculated are: global hardness $(\eta)$, softness $(\sigma)$ and the fraction of electron transfer $(\Delta N)$ from the metal atom using the following equations, respectively. ${ }^{32,33}$

$$
\begin{aligned}
& \Delta E=E_{\text {LUMO }}-E_{\text {Номо }} \\
& \eta=\frac{1}{2}\left(E_{\text {LUMO }}-E_{\text {HOMO }}\right) \\
& \sigma=\frac{1}{\eta} \\
& \Delta N=\frac{\phi-\chi_{\mathrm{inh}}}{2\left(\eta_{\mathrm{Fe}}+\eta_{\mathrm{inh}}\right)}
\end{aligned}
$$

where, $\chi_{\mathrm{Fe}}$ and $\chi_{\text {inh }}$ denote the absolute electronegativity of iron and the inhibitor molecule respectively; $\eta_{\mathrm{Fe}}$ and $\eta_{\text {inh }}$ denote the absolute hardness of iron and the inhibitor molecule respectively. The values of $\phi$ and $\eta_{\mathrm{Fe}}$ are taken as 4.82 and $0 \mathrm{eV}^{-1} .{ }^{31}$ The local nucleophilic and electrophilic sites were calculated using UCA-FUKUI v 1.0 software $^{32}$ via Finite Difference (FD) method with the use of the output file from Gaussian 09. The Fukui function $\left(f_{\mathrm{k}}\right)$ is the first derivative of the electronic density $\rho(\vec{r})$ with respect to the number of electrons $\mathrm{N}$, in a constant external potential $v(\vec{r})$ and written as follows: ${ }^{33,34}$

$f_{k}=\left(\frac{\partial \rho(\vec{r})}{\partial N}\right)_{v(\vec{r})}$

Fukui functions favoring electrophilic and nucleophilic attacks can be determined as: ${ }^{35}$
$f_{k}^{-}=q_{k}(N)-q_{k}(N-1)$ (For electrophilic attack)

$f_{k}^{+}=q_{k}(N+1)-q_{k}(N)$ (For nucleophilic attack)

$f k^{0}=\frac{q_{k}(N+1)-q_{k}(N-1)}{2}$

Where, $k$ is gross charge of the atom denoted by $q_{\mathrm{k}}$. The $q_{k}$ $(N+1), q_{\mathrm{k}}(N)$ and $q_{\mathrm{k}}(N-1)$ are the charges of the anionic, neutral and cationic species, respectively.

2.2e Monte Carlo simulations: Monte Carlo simulations (MC) were performed using Forcite and Adsorption Locator modules in the material studio software 7.0 from BIOVIA- Accelrys (U.S.A.) The simulation was carried out with $\mathrm{Fe}$ (110) crystal with a slab of $5 \AA$. The Fe (110) plane was enlarged to $\mathrm{a}(10 \times 10)$ super cell to provide a large surface for the interaction of the inhibitors. After that, a vacuum slab with $30 \AA$ A thickness was built above the Fe (110) plane. The condensed-phase optimized molecular potentials for atomistic simulation studies (COMPASS) force field were used to optimize the structures of all components of the system of interest including the corrosion inhibitors. Similar procedure has been documented elsewhere. ${ }^{36-39}$ The MC simulations for the studied inhibitors were carried out in gas and aqueous phase. 100 water molecules were introduced into the simulation box to simulate a realistic aqueous corrosive environment. The simulated annealing procedure adopted in this study uses the Monte Carlo method to determine the adsorption energy of the adsorbate substrate. During the simulated annealing, the adsorbate was heated and then cooled very slowly so that conformational changes will lead to a local minimum being located. The process was repeated several times until very closely related, low energy conformations were obtained.

\section{Results and Discussion}

\subsection{Gravimetric measurement}

3.1a Effect of inhibitor concentration: The variation of inhibition efficiency with inhibitor concentrations is shown in Figure 2a. It is observed from the figure that the inhibition efficiency increases as the concentration of inhibitors increases. The obtained results indicate that the corrosion inhibition efficiency of the DAPs is concentration dependent. DAP-1 showed the maximum inhibition efficiency of $98.5 \%$ among the three studied inhibitors at the optimum concentration of $40 \mathrm{mgL}^{-1}$ and no change was observed in the inhibition efficiency above this concentration, and thus $40 \mathrm{mgL}^{-1}$ was chosen as optimum. The superior performance of DAP-1 is attributed to the presence of electron donating methyl group and the low inhibition efficiency of DAP-3 is due to the presence of electron withdrawing $\mathrm{NO}_{2}$ group. Functional groups play an important role in the inhibition efficiency. ${ }^{40}$ The increase in inhibition efficiency is 

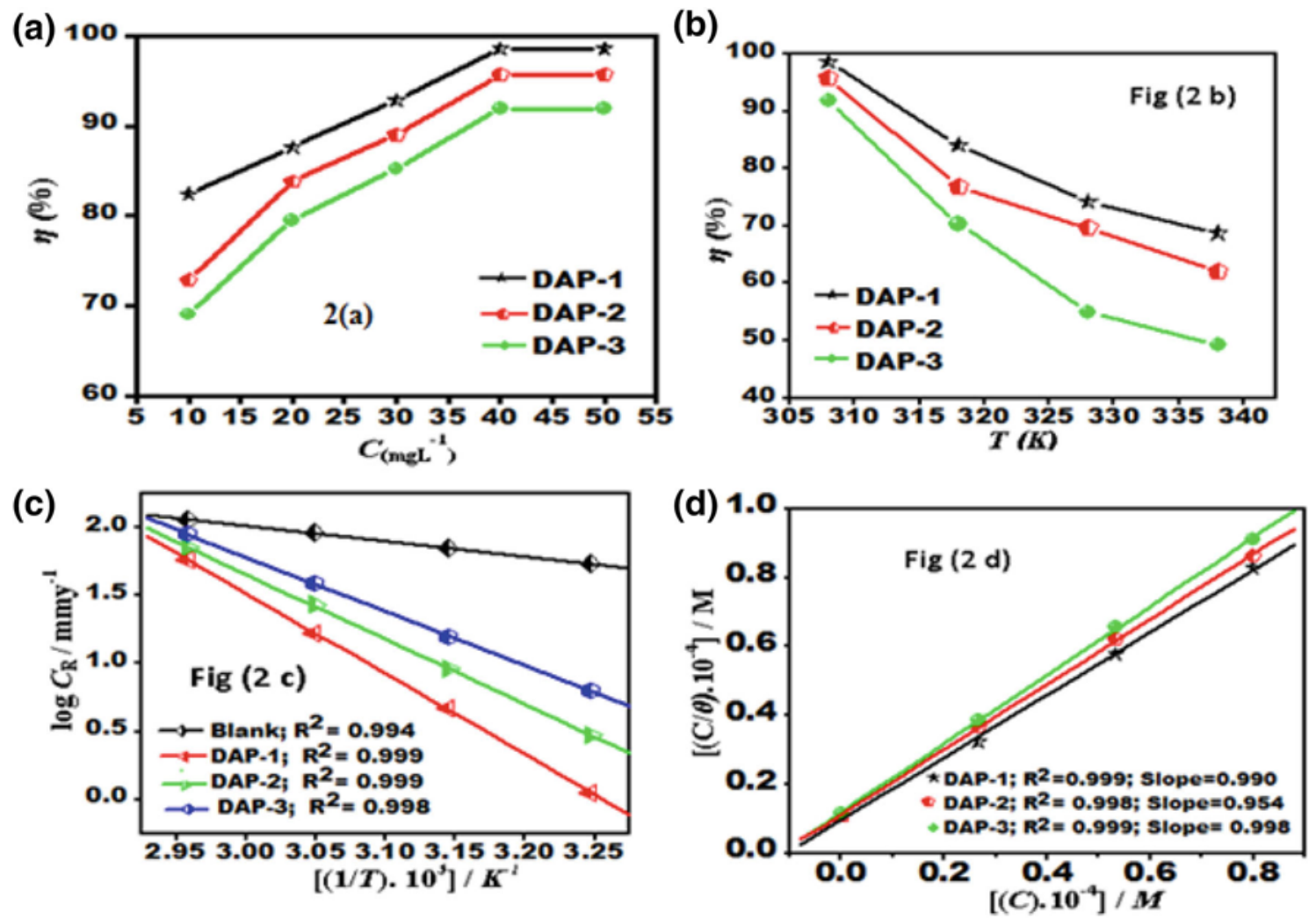

Figure 2. (a) Variation of the inhibition efficiency ( $\eta \%$ ) with inhibitor concentration at $308 \mathrm{~K}$; (b) Variation of inhibition efficiency $(\eta \%)$ with solution temperature $(308-338 \mathrm{~K})$ at optimum concentration of inhibitor DAPs; (c) Arrhenius plots of the corrosion rate $\left(C_{R}\right)$ of $\mathrm{MS}$ in $1 \mathrm{M} \mathrm{HCl}$ in the absence and presence of optimum concentration of DAPs; (d) Langmuir isotherm plot for adsorption of DAPs on MS surface in $1 \mathrm{M}$ $\mathrm{HCl}$.

attributed to an increase in the extent of surface coverage by the inhibitor molecules on the metal surface. ${ }^{40}$

3.1b Effect of temperature: The variation in inhibition efficiency with temperature (308-338K) is shown in Figure 2b. From Figure 2b, it is seen that inhibition efficiency of the DAPs decrease with an increase in temperature. The decrease in inhibition efficiency is due to the partial desorption of inhibitors molecule from the metal surface. ${ }^{41}$ The temperature dependence of corrosion rate (CR) was estimated using Arrhenius equation (Table 2).

$$
\begin{aligned}
& \log C_{R}=\frac{-E_{a}}{2.303 R T}+\lambda \\
& C_{R}=\frac{R T}{N h} \exp \left(\frac{\Delta S^{*}}{R}\right) \exp \left(-\frac{\Delta H^{*}}{R T}\right)
\end{aligned}
$$

Where, $E_{\mathrm{a}}$ is the activation energy of the corrosion process, $R$ is the gas constant, and $\lambda$ is the Arrhenius preexponential factor; $N$ is the Avogadro number, $h$ is the Planck's constant, $R$ is the gas constant, $T$ is the absolute temperature, $\Delta S^{*}$ is the entropy of activation and $\Delta H^{*}$ denotes the enthalpy of activation. The values of $\Delta S^{*}$ and $\Delta H^{*}$ were calculated from the plot of $\log C_{R} / T$ vs $1 / T$ (with a slope of $\Delta H^{*} / 2.303 R$ and an intercept of $\left[\log (R / N h)+\left(\Delta S^{*} / 2.303 R\right)\right]$ is a straight line in both in the absence the presence of inhibitor. The values of $\Delta H^{*}$ and $\Delta S^{*}$ are given in Table 3. Positive sign of $\Delta H^{*}$ reflected the endothermic nature of mild steel dissolution process, which suggested the slow dissolution of mild steel. ${ }^{41}$ The positive $\Delta S^{*}$ means that an increase in disorder takes place in going from reactants to the activated complex on the metal/solution interface, ${ }^{40}$ which is the driving force for the adsorption process.

The activation energy $\left(E_{\mathrm{a}}\right)$ values were calculated by plotting a graph between $\log C_{\mathrm{R}}$ vs $1 / T$ at an optimum concentration of inhibitors and are shown Figure 2c. The calculated values of $E_{\mathrm{a}}$ in the absence and presence of inhibitor molecules are shown in Table 3 (Thermodynamic parameters for the adsorption of the inhibitor on mild steel in $1 \mathrm{M} \mathrm{HCl}$ at the optimum concentration $\left(40 \mathrm{mgL}^{-1}\right)$ DAPs). On inspection of Table 3 , the value of activation energy is higher in the presence of inhibitors than in the absence because of the increase in the physical energy barrier associated with the corrosion reaction. The higher activation energy and a decrease in 
Table 2. Gravimetric Measurements $( \pm \mathrm{SD})$ for MS in the Absence and Presence of DAPs in $1 \mathrm{M} \mathrm{HCl}$ at $308 \mathrm{~K}$.

\begin{tabular}{lcccc}
\hline Inhibitor & Concentration $\left(\mathrm{mgL}^{-1}\right)$ & $C_{\mathrm{R}} \mathrm{mg} \mathrm{cm}^{-2} \mathrm{~h}^{-1}$ & Surface coverage $(\theta)$ & $(\eta) \%$ \\
\hline Blank & - & $7.00(0.03)$ & - & - \\
DAP-1 & 10 & $1.23(0.01)$ & 0.823 & 82.3 \\
& 20 & $0.86(0.01)$ & 0.876 & 87.6 \\
& 30 & $0.50(0.02)$ & 0.928 & 92.8 \\
& 40 & $0.10(0.02)$ & 0.985 & 98.5 \\
DAP-2 & 50 & $0.10(0.02)$ & 0.985 & 98.5 \\
& 10 & $1.90(0.01)$ & 0.728 & 72.8 \\
& 20 & $1.13(0.01)$ & 0.838 & 83.7 \\
& 30 & $0.76(0.03)$ & 0.890 & 89.0 \\
DAP-3 & 40 & $0.30(0.03)$ & 0.957 & 95.7 \\
& 50 & $0.30(0.03)$ & 0.957 & 95.7 \\
& 10 & $2.16(0.02)$ & 0.690 & 69.0 \\
& 20 & $1.43(0.03)$ & 0.758 & 75.8 \\
& 30 & $1.33(0.02)$ & 0.852 & 85.2 \\
& 40 & $0.56(0.03)$ & 0.919 & 91.9 \\
& 50 & $0.56(0.03)$ & 0.918 & 91.8 \\
\hline
\end{tabular}

Table 3. Thermodynamic parameters for the adsorption of inhibitor on mild steel in $1 \mathrm{M} \mathrm{HCl}$ at optimum concentration $\left(40 \mathrm{mgL}^{-1}\right)$ of DAPs at $308 \mathrm{~K}$.

\begin{tabular}{lccccc}
\hline Inhibitor & $K_{\text {ads }}\left(10^{4} M^{-}\right)$ & $-\Delta G_{\text {ads }}^{\circ}\left(\mathrm{kJ} \mathrm{mol}^{-1}\right)$ & $E_{\mathrm{a}}\left(\mathrm{kJ} \mathrm{mol}^{-1}\right)$ & $\Delta H^{*}\left(\mathrm{kJmol}^{-1}\right)$ & $\Delta S^{*}\left(\mathrm{JK}^{-1} \mathrm{~mol}^{-1}\right)$ \\
\hline Blank & - & - & 28.74 & 24.89 & -149.17 \\
DAP-1 & 5.8 & 40.16 & 117.38 & 111.0 & 116.2 \\
DAP-2 & 3.4 & 39.19 & 113.38 & 89.61 & 54.58 \\
DAP-3 & 1.3 & 38.67 & 91.17 & 73.35 & 8.63 \\
\hline
\end{tabular}

the corrosion rate might be due to the formation of a protective film of inhibitors on the metal surface. ${ }^{40}$ Table 3 shows that in the presence of DAPs, $E$ a and $\Delta H^{*}$ values change in a similar manner, which verifies the known thermodynamic relationship between $E$ a and $\Delta H^{*}$.

$\Delta H *=E \mathrm{a}-R T$

The $\Delta S^{*}$ values (shown in Table 3) for uninhibited are large and negative and for the inhibited DAPs molecules it is large and positive. This variation is observed due to the disordering and ordering of the DAPs molecules on the mild steel surface. The higher value for the $\Delta S^{*}$ in the presence of inhibitors than in the absence of inhibitors is due to the adsorption of DAP molecules solution which may be due to the quasi-substitution process between the DAP molecules and the water molecules on the mild steel surface, ${ }^{42-44}$ by which the adsorption of DAPs molecule and desorption of water molecules from the mild steel surface take place.

3.1c Adsorption isotherm: In order to understand the behavior of DAPs on mild steel in $1 \mathrm{M} \mathrm{HCl}$, various adsorption isotherms, namely, Langmuir, Temkin and
Frumkin were tested. Langmuir adsorption isotherm provided the best fit among the studied isotherms. It is represented by the following equation ${ }^{45}$

$\frac{C_{\mathrm{inh}}}{\theta}=\frac{1}{K_{\mathrm{ads}}}+C_{\mathrm{inh}}$

Where, $K_{\text {ads }}$ is the adsorption equilibrium constant process, $C$ is the concentration of the inhibitor and $\theta$ is surface coverage value. A straight line was observed by plotting a graph between $\log \left(C_{\mathrm{inh}} / \theta\right)$ vs. $C_{\mathrm{inh}}$ as shown in Figure $2 \mathrm{~d}$, which suggested the adsorption of inhibitor molecules on the metal surface obeys Langmuir isotherm.

The values of $K_{\text {ads }}$ in association with the standard Gibbs free energy of adsorption $\Delta G_{\text {(ads) }}^{\mathrm{o}}$ was obtained from the Langmuir adsorption isotherm by the following equation. ${ }^{46}$

$K_{a d s}=\frac{1}{C_{(s o l .)}} \exp \left(\frac{\Delta G_{a d s}^{0}}{R T}\right)$

Where, $R$ is universal gas constant, $T$ is the absolute temperature and $C$ is the concentration of water $(1000 \mathrm{~g} / \mathrm{L})$. The values of $K_{\text {ads }}$ are represented here in 
$\mathrm{g}^{-1} \mathrm{~L}$. Thus, in this equation, the concentration of water is taken in $\mathrm{g} / \mathrm{L}(1000 \mathrm{~g} / \mathrm{L})$ in the place of $55.5 \mathrm{~mole} / \mathrm{L}$. The values of $K_{\text {ads }}$ and $\Delta G_{(\text {ads })}^{\mathrm{o}}$ are reported in Table 3. The calculated values of $K_{\text {ads }}$ and $\Delta G^{0}$ ads are given in Table 3. Generally, a higher value of $K_{\text {ads }}$ is associated with strong adsorption and higher inhibition. In our present study, the value of $K_{\text {ads }}$ obeys the order: DAP-1 > DAP-2 > DAP-3 which is in accordance with the order of inhibition efficiency. From the literature, it is noted that if the value of $\Delta G_{\mathrm{ads}}^{0}$ is around $-20 \mathrm{kJmol}^{-1}$, the adsorption may be due to the electrostatic interactions (physisorptions) and if the $\Delta G_{\text {ads }}^{0}$ is around the $-40 \mathrm{kJmol}^{-1}$ then the adsorption is chemisorption. The value of $\Delta G_{(\text {ads })}^{o}$ for the present study varies from -38.17 to $-40.16 \mathrm{~kJ} \mathrm{~mol}^{-1}$, suggesting that the adsorption of inhibitors on the mild steel surface is by mixed mode. ${ }^{47,48}$

\subsection{Electrochemical impedance spectroscopy}

The Nyquist plots obtained for mild steel in $1 \mathrm{M}$ $\mathrm{HCl}$ with and without the optimum concentration $\left(40 \mathrm{mgL}^{-1}\right)$ of the inhibitors are shown in Figure $3 \mathrm{a}$. The Nyquist plots are slightly depressed semi-circular curves. This feature might be due to different factors like surface roughness, discontinuity in the electrodes, impurities and the inhibitors adsorption on the electrode surface. The shapes of uninhibited and inhibited mild steel in $1 \mathrm{M} \mathrm{HCl}$ are same which suggests that DAPs reduce corrosion without changing the mechanism of corrosion. ${ }^{49-51}$ Figure 3 a shows that the addition of DAPs increases the diameter of the semicircle which signifies that the corrosion is controlled by the charge transfer process and inhibition is attributed to the formation of a protective film on the mild steel surface. The fitted Nyquist plots of DAPs are shown in Figure 3(c-e).

The electrochemical impedance parameters such as, polarization resistance (Rp), solution resistance (Rs), magnitude of CPE (Yo) and heterogeneity (n) were calculated by fitting the impedance spectra to the equivalent circuit model shown in Figure $3 \mathrm{~b}$ and are tabulated in Table 4 (Electrochemical impedance parameters $( \pm$ SD) for mild steel in $1 \mathrm{M} \mathrm{HCl}$ in the absence and presence of optimum concentration $\left(40 \mathrm{mg} \mathrm{L}^{-1}\right)$ of DAPs at $308 \mathrm{~K})$. The circuit is a parallel combination of $R_{\mathrm{p}}$ and the constant phase element (CPE) of a double layer. The percentage inhibition efficiency $(\eta \%)$ by using $R_{\mathrm{p}}$ is expressed as, ${ }^{50}$

$\eta \%=\left(\frac{R_{p(i)}-R_{p}}{R_{p(i)}}\right) \times 100$ where, $R \mathrm{p}$ represents the polarization resistance in the presence and the absence of the DAPs at optimum concentration, which is the sum of $R_{\mathrm{ct}}$ and $R_{\mathrm{f}}$. Here, $R_{\mathrm{f}}$ is the film resistance. The data in Table 4 show that $R_{\mathrm{p}}$ increases with the increasing inhibitor concentration, which indicates the enhancement of surface resistance by the inhibitor molecules and the increasing inhibition of mild steel corrosion. ${ }^{52}$ However, the CPE values decrease with the increase in inhibitor concentration due to adsorption of inhibitor molecules on the metal surface. ${ }^{52,53}$ The increase in the $R_{\mathrm{p}}$ value for the inhibited system is due to the formation of the protective film on the metal/solution interface. ${ }^{53}$ The value of $C_{\mathrm{dl}}$ decreases with increasing concentration of DAPs due to the decrease in local dielectric constant or an increase in the electrical double layer thickness at the metal surface. ${ }^{54}$ The imperfect semicircle of the Nyquist plots has been related to the deviation of $\mathrm{n}$ from unity (surface inhomogeneity); that is, the pure capacitive behavior could not be achieved due to surface inhomogeneity caused by interfacial and structural origin. The double layer is usually considered as a constant phase element (CPE) rather than a pure capacitor. The CPE is placed for the capacitor to fit the semicircle more accurately and expressed as:

$Z_{C P E}=Y_{o}^{-1}(j \omega)^{-n}$

Where, $Z_{C P E}$ is the impedance of CPE, $Y_{o}$ is the CPE coefficient (admittance or reciprocal of impedance) and $\omega$ is the angular frequency given by $\omega=2 \pi f$ (having units in $\mathrm{rad} \mathrm{sec}^{-1}$ ). According to the above equation, the phase angle of the CPE impedance becomes independent of frequency having a value of $(-n \pi / 2)$ degrees. Hence, the CPE is called the "constant phase element". The numerical value of $n$ is given by the slope of the linear region of the Bode plot. When the value of $n$ reaches unity, the equation becomes,

$\frac{1}{Z_{C P E}}=Y_{o} j \omega=j \omega C$

Thus, the CPE behaves as a capacitor when $n$ is close to $1 .{ }^{55,56}$ The double layer capacitance $\left(C_{d l}\right)$ can be evaluated as follows:

$C_{d l}=\frac{Y_{o} \omega^{n-1}}{\sin (n(\pi / 2))}$

Where, $\omega$ is given by $\omega_{\max }=2 \pi f_{\max }$ at which the imaginary part of the impedance $\left(-Z_{i m}\right)$ is maximum and other symbols are as defined above. Moreover, the value of $n$ can also be used to represent the nature of $\mathrm{CPE}$, such that CPE characterizes a resistance when $\mathrm{n}=0\left(Y_{0}=\mathrm{R}\right)$; capacitance when $\mathrm{n}=1\left(Y_{0}=\mathrm{C}\right)$; inductance when $\mathrm{n}=-1\left(Y_{0}=1 / \mathrm{L}\right)$; or Warburg 


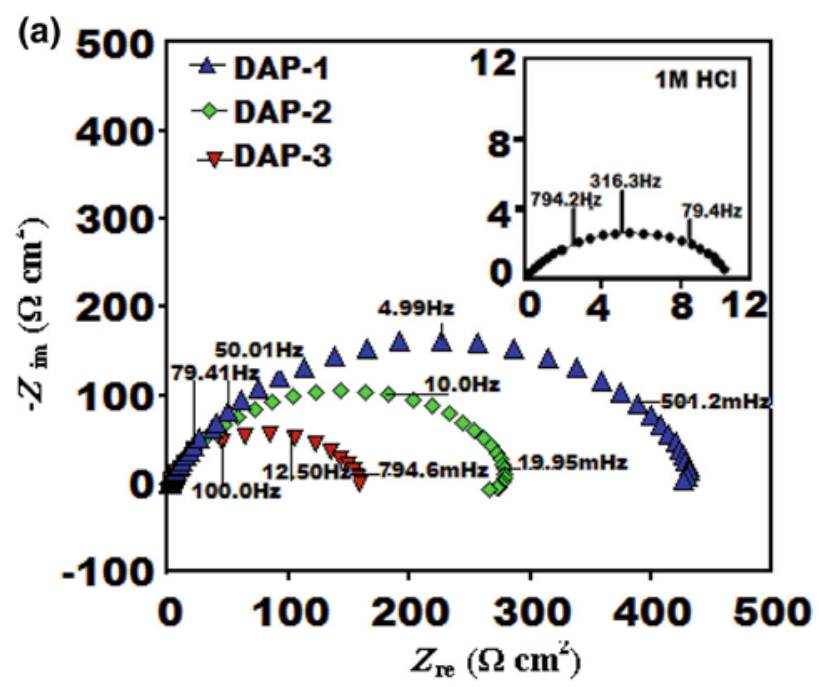

(b)

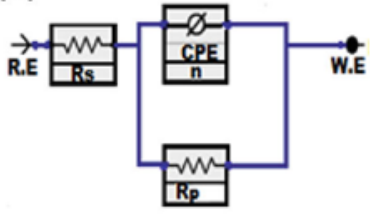

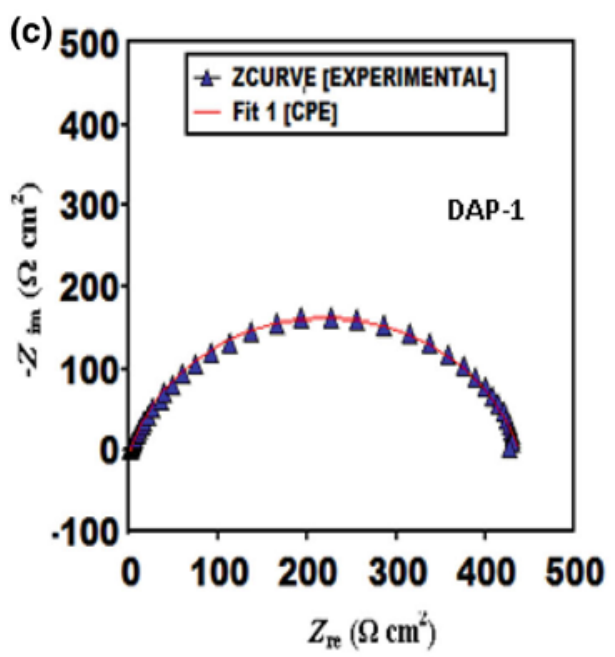
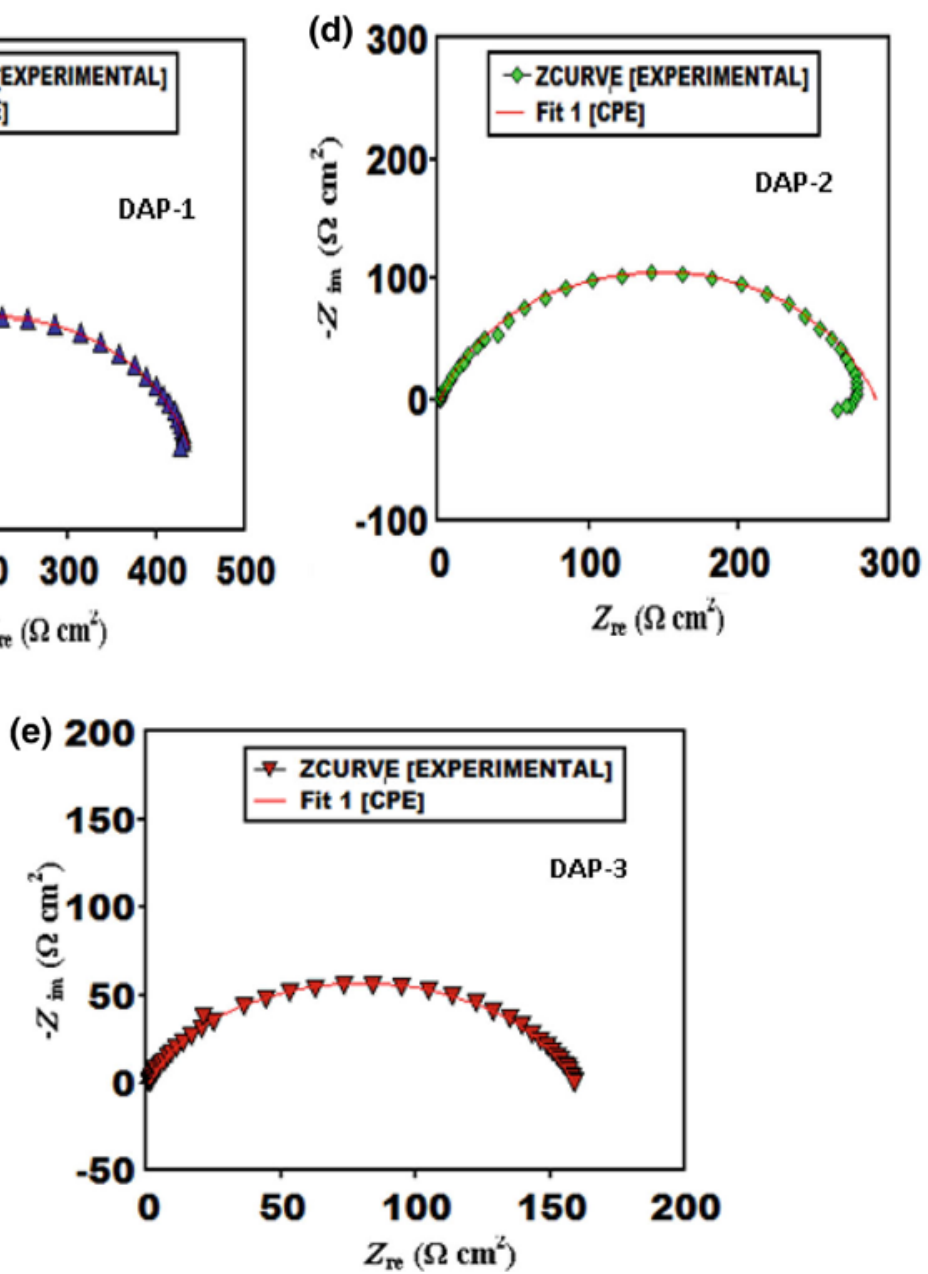

Figure 3. (a) Nyquist plots for the mild steel at optimum concentration of inhibitors DAP at $308 \mathrm{~K}$; (b) Equivalent circuit model used to fit the EIS data; (c) (d) (e): fitted Nyquist plot for DAP-1, DAP-2, DAP-3 respectively; (f) Bode ( $\log f$ vs $\log |Z|)$ and phase angle ( $\log f$ vs $\alpha$ ) plots of impendence spectra for MS in $1 \mathrm{M} \mathrm{HCl}$ in the absence and presence of different concentrations of DAP at $308 \mathrm{~K}$; (g) (h) (i): fitted bode plots for DAP-1, DAP-2, DAP-3, respectively. 

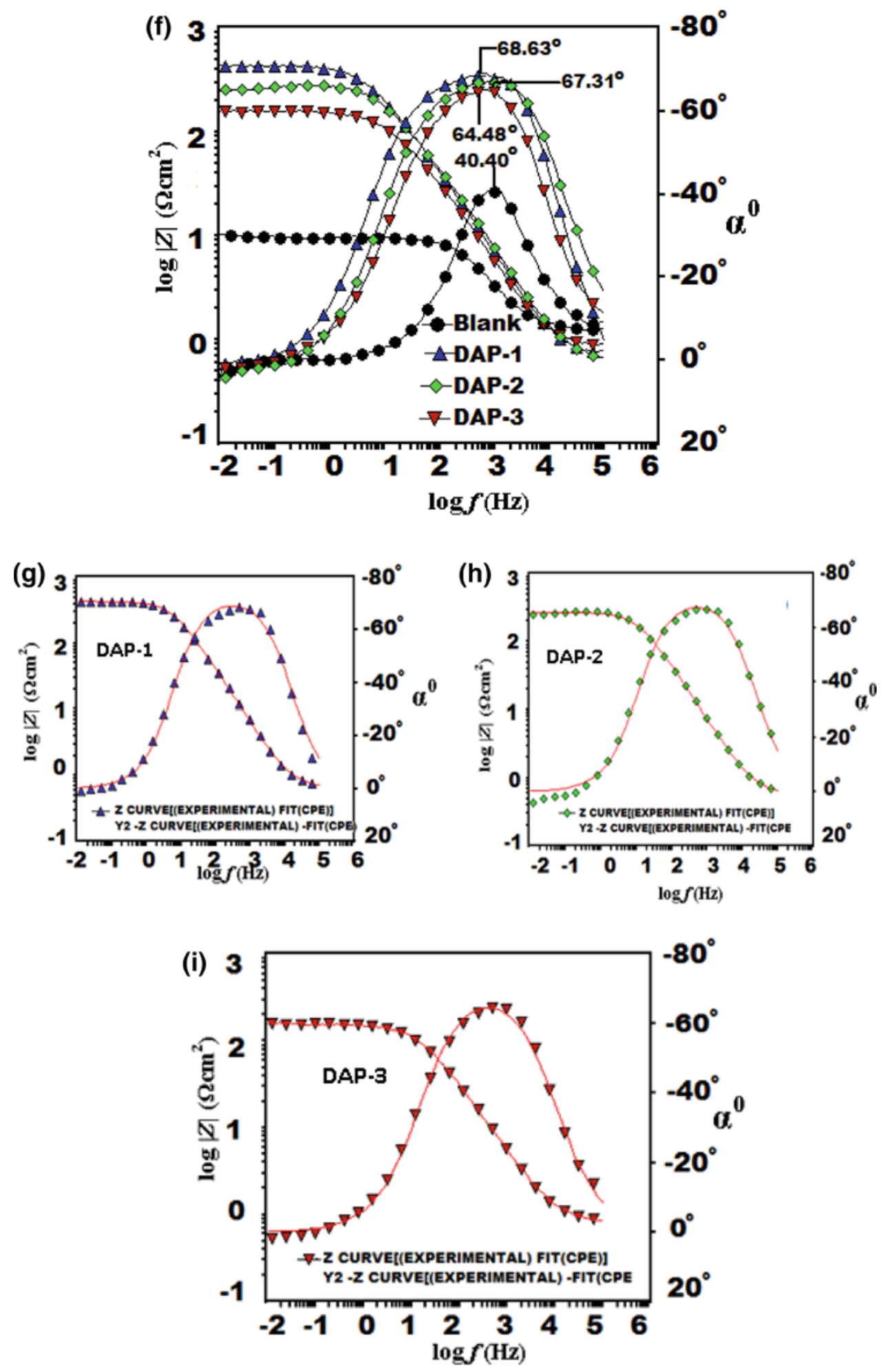

Figure 3. continued

impedance when $\mathrm{n}=0.5(\mathrm{Y} 0=\mathrm{W})$. The values of the EIS parameters obtained after the spectra fitting are listed in Table 4 . The results in Table 4 show that $n$ varies from 0.799 to 0.816 in the presence of the inhibitors, which is comparatively higher than that of the blank, suggesting that surface heterogeneity decreases in the presence of inhibitors due to formation of protective film on the steel surface.

Bode plots are shown in Figure 3f. It is seen that Bode plots involve only one phase maximum revealing 
Table 4. Electrochemical impedance parameters $( \pm \mathrm{SD})$ for mild steel in $1 \mathrm{M} \mathrm{HCl}$ in the absence and presence of optimum concentration $\left(40 \mathrm{mg} \mathrm{L}^{-1}\right)$ of DAPs at $308 \mathrm{~K}$.

\begin{tabular}{lcccccc}
\hline$C_{\text {inh }}\left(\mathrm{mgL}^{-1}\right)$ & $R_{\mathrm{s}}(\Omega)$ & $R_{\mathrm{p}}\left(\Omega \mathrm{cm}^{2}\right)$ & $n$ & $Y_{0}\left(\mu \mathrm{Fcm}^{-2}\right)$ & $C_{\mathrm{dl}}\left(\mu \mathrm{Fcm}^{-2}\right)$ & $\eta(\%)$ \\
\hline Blank & $1.02(0.02)$ & $7.44(0.05)$ & 0.798 & 481.2 & 137.9 & - \\
DAP-1 & $0.658(0.02)$ & $433.3(0.03)$ & 0.816 & 120.7 & 52.35 & 98.05 \\
DAP-2 & $0.567(0.02)$ & $217.7(0.05)$ & 0.805 & 125.7 & 75.04 & 96.10 \\
DAP-3 & $0.786(0.02)$ & $157.0(0.03)$ & 0.799 & 174.8 & 104.9 & 94.58 \\
\hline
\end{tabular}

that corrosion process takes place in one step, which corresponds to one time constant. ${ }^{57}$ It is also seen that from Figure $3 \mathrm{f}$ that phase angle value is less than $-90^{\circ}$, which signified the non-ideal behavior of capacitor. The more negative value of phase angle and the high value of absolute impedance in the presence of DAPs indicate the superior performance of DAPs. ${ }^{58,59}$ The fitted Bode plots of DAPs are shown in the Figures $3(\mathrm{~g}-\mathrm{i})$.

\subsection{Potentiodynamic polarizations study}

The potentiodynamic polarisation plots (PDP) for MS in $1 \mathrm{M} \mathrm{HCl}$ in the absence and presence of DAPs at the optimum concentration of $40 \mathrm{mgL}^{-1}$ are shown in Figure 4 . The calculated PDP parameters such as corrosion current density $\left(i_{\text {corr }}\right)$, corrosion potential $\left(E_{\text {corr }}\right)$, anodic Tafel slope $\left(\beta_{\mathrm{a}}\right)$, cathodic Tafel slope $\left(\beta_{\mathrm{c}}\right)$ and the inhibition efficiency $(\eta \%)$ are given in Table 5 . The $\eta \%$ was calculated using the following equation:

$\eta \%=\frac{i_{\text {corr }}-i_{\text {corr (inh) }}}{i_{\text {corr }}} \times 100$

where, $i_{\text {corr }}$ and $i_{\text {corr(i) }}$ are the uninhibited and inhibited corrosion current densities, respectively. Figure 4 clearly shows that the addition of DAPs causes reduction of $i_{\text {corr }}$ without causing a significant change in $E_{\text {corr }}$, thereby suggesting that all DAPs are good corrosion inhibitors and act as mixed inhibitors. ${ }^{58}$ The parallel cathodic Tafel lines (Figure 4) suggest that the addition of inhibitors does not modify the mechanism of corrosion reaction. ${ }^{41}$ On addition of the DAPs, the values for both anodic and cathodic Tafel slopes $\left(\beta_{\mathrm{a}}, \beta_{\mathrm{c}}\right)$ slightly change, which indicates that the addition of the inhibitor reduces the anodic dissolution of mild steel as well as retards the cathodic hydrogen evolution reaction, without affecting the reaction mechanism. ${ }^{60}$

\subsection{Surface analysis}

For the surface characterization, scanning electron microscopy (SEM) and atomic force microscopy (AFM) have become most powerful tools for analyzing the of

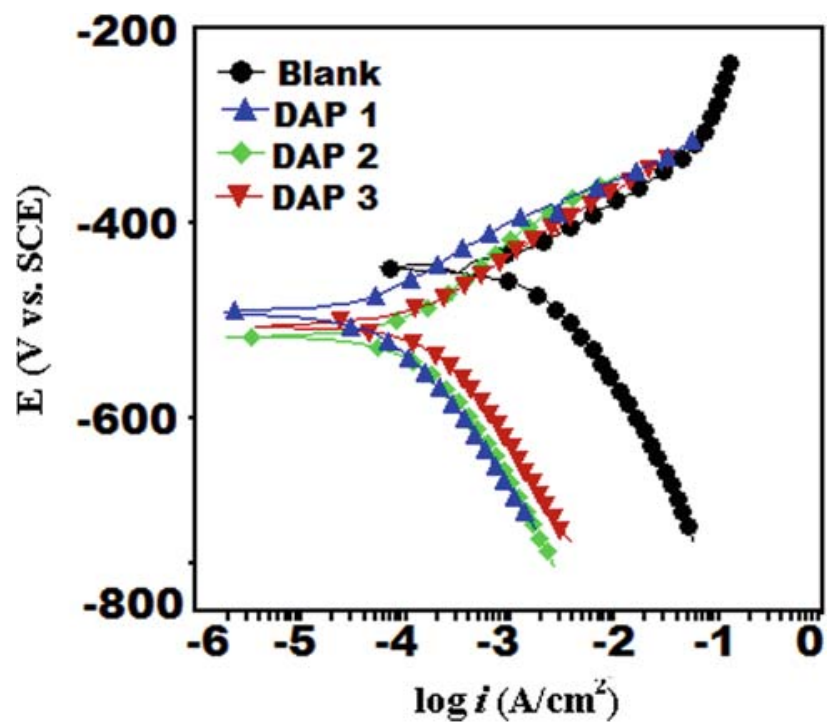

Figure 4. Polarization curves for corrosion of mild steel in the absence and presence of optimum concentrations of inhibitors.

surface of corroded specimens. From the SEM, the morphology of the metal surface and the accumulation of the corrosion products on the metal can be examined. Figures 5(a-d) (SEM image of mild steel, (a) Blank, (b) DAP-1, (c) DAP-2, and (d) DAP-3), respectively, show the SEM image of uninhibited and inhibited mild steel samples in $1 \mathrm{M} \mathrm{HCl}$ for $24 \mathrm{~h}$ of the immersion period at the optimum concentration $\left(40 \mathrm{mgL}^{-1}\right)$ of the inhibitors. The surface of the uninhibited mild steel specimen is highly corroded due to acid attack but in the presence of the inhibitors, the surface is relatively smooth.

The AFM analysis was performed on steel surface after the immersion of samples in acid solutions up to $24 \mathrm{~h}$. The micrographs of the mild steel samples in the absence and the presence of the inhibitors at the optimum concentration $\left(40 \mathrm{mgL}^{-1}\right)$ are shown in Figure 6(a-d) (AFM image of mild steel, (a) Blank, (b) DAP-1, (c) DAP-2, and (d) DAP-3, respectively). The micrograph of the mild steel surface in the absence of inhibitor is $400 \mu \mathrm{m}$ and in the presence of inhibitors, there is a significant improvement in the smoothness due to the adsorption of the inhibitors on the 
Table 5. Potentiodynamic polarization parameters $( \pm S D)$ for mild steel in $1 \mathrm{M} \mathrm{HCl}$ in absence and presence of optimum concentration $\left(40 \mathrm{mg} \mathrm{L}^{-1}\right)$ of DAPs at $308 \mathrm{~K}$.

\begin{tabular}{lccccc}
\hline Inhibitor & $E_{\text {corr }}(\mathrm{mV} / \mathrm{SCE})$ & $i_{\text {corr }}\left(\mu \mathrm{A} / \mathrm{cm}^{2}\right)$ & $\beta_{\mathrm{a}}(\mathrm{mV} / \mathrm{dec})$ & $-\beta_{\mathrm{c}}(\mathrm{mV} / \mathrm{dec})$ & $\eta(\%)$ \\
\hline Blank & -445 & $1320(0.03)$ & 74.6 & 123.9 & - \\
DAP-1 & -492 & $29.3(0.02)$ & 64.4 & 105.6 & 96.7 \\
DAP-2 & -517 & $79.8(0.02)$ & 109.1 & 149.6 & 91.0 \\
DAP-3 & -505 & $109.4(0.03)$ & 86.1 & 139.3 & 87.7 \\
\hline
\end{tabular}
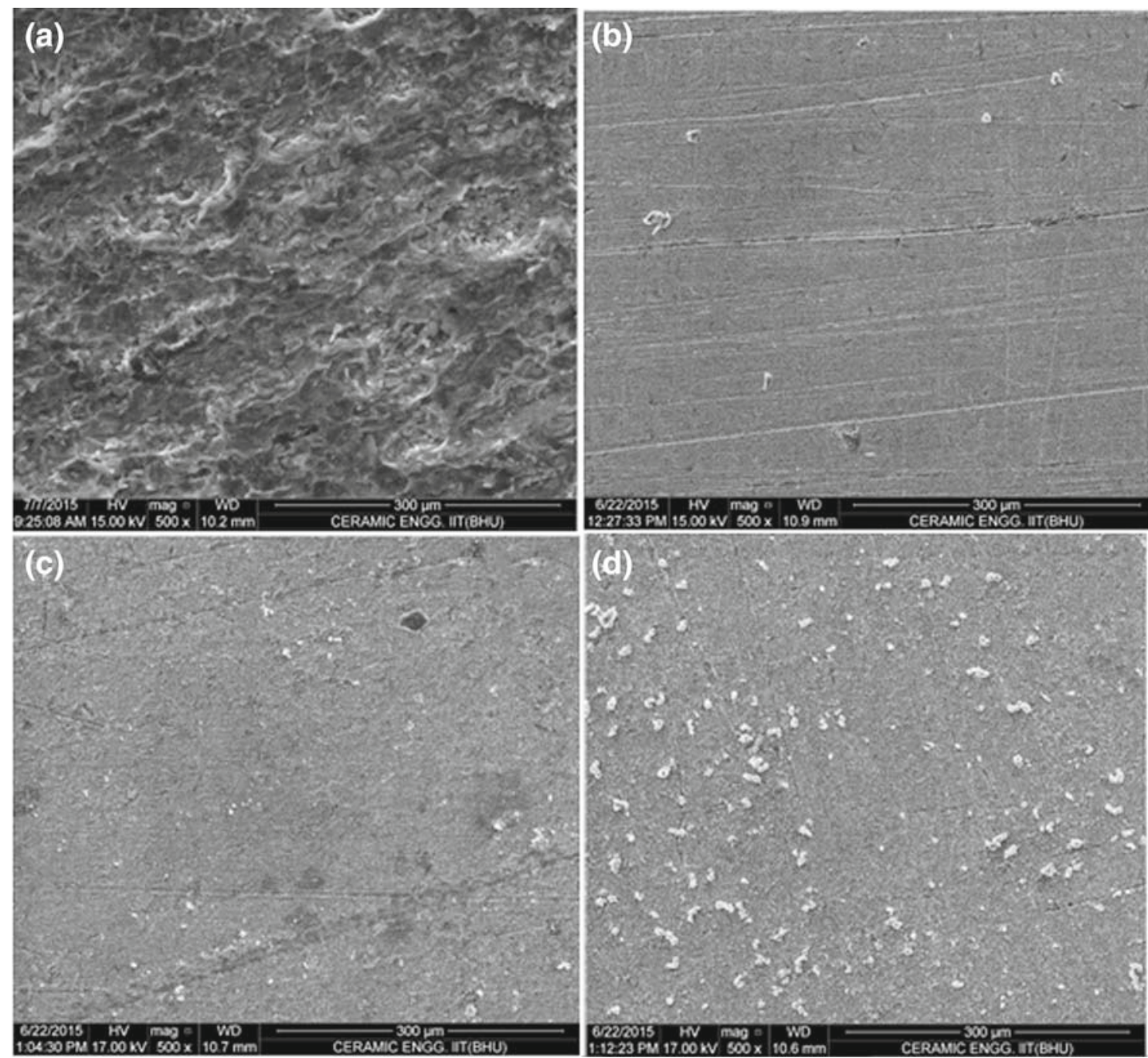

Figure 5. SEM images for, (a) Blank, (b) DAP-1, (c) DAP-2, and (d) DAP-3.

metal surface. The calculated average roughness for DAP-1, DAP-2 and DAP-3 are 0.6, 5.2 and $10.0 \mu \mathrm{m}$, respectively.

\subsection{Quantum chemical calculations}

3.5a Quantum chemical calculations of neutral inhibitor molecules: Frontier molecular orbitals: For understanding the donor-acceptor relationship between the frontier molecular orbital's (FMOs) of the inhibitor molecules and the metallic surface, HOMO and LUMO were studied. Figure 7 shows the optimized structures, $\mathrm{HOMO} / \mathrm{LUMO}$, and ESP of the corresponding corrosion inhibitors. The Mullikan charges are given in the Table 6. Generally HOMO and LUMO represent the electron donating and electron accepting capacity of the molecules. ${ }^{61}$ Molecules with higher value of $E_{\mathrm{HOMO}}$ (less negative) and lower value of $E_{\text {LUMO }}$ (more negative) show greater donor and acceptor tendency with appropriate metal d-orbital, respectively. ${ }^{62-64}$ 

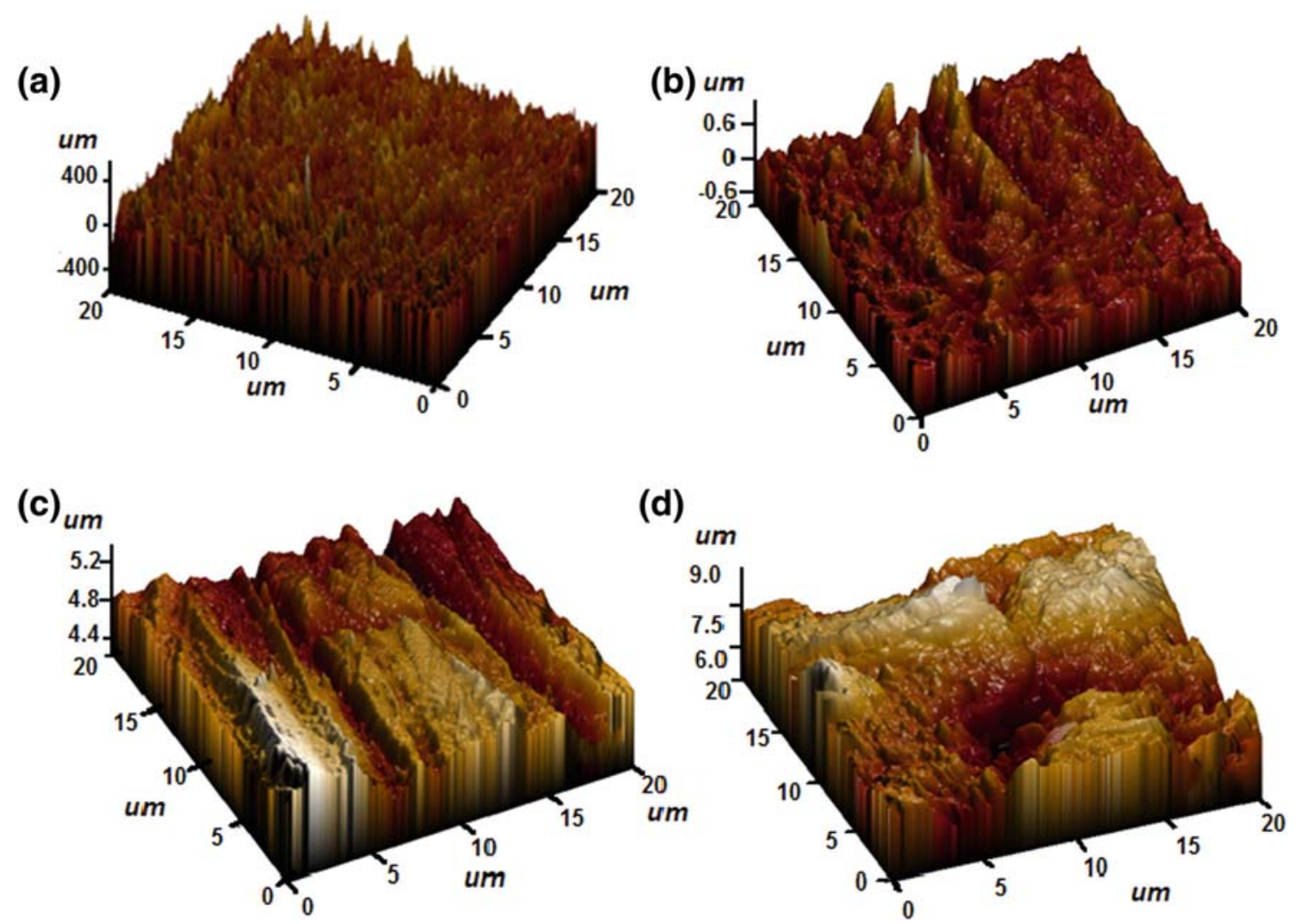

Figure 6. AFM images for, (a) Blank, (b) DAP-1, (c) DAP -2, and (d) DAP -3.

It can be seen that in the case of neutral inhibitor molecules (DAP-1, DAP-2 and DAP-3), the HOMO electrons are spread over the phenyl ring and nitrogen atoms of the diaminopyridine ring. In the LUMO regions for DAP-1, DAP-2, the electron density resides all over the ring and in the case of DAP-3, the electron density is spread over the phenyl ring, nitrogen atoms of the diaminopyridine ring and over the nitro group.

Frontier molecular orbital energies: The calculated quantum parameters like $E_{\mathrm{HOMO}}, E_{\mathrm{LUMO}}, \Delta E\left(E_{\mathrm{LUMO}}-\right.$ $\left.E_{\text {номо }}\right)$ are listed in Table 7 . The difference in energy level $\Delta E$ is an important factor and considered in the evaluation of inhibition potential. Generally, higher value of $E_{\text {Номо }}$ suggests better donor performance of the inhibitor molecules. Table 7 reveals that the value of $E_{\mathrm{HOMO}}$ for DAP-1 is larger than that of DAP-2 and DAP-3, which supports the order of inhibition efficiencies obtained experimentally. The highest $E_{\mathrm{HOMO}}$ value for DAP-1 is due to the presence of electron donating $\mathrm{CH}_{3}$ group attached to phenyl ring while lowest $E_{\mathrm{HOMO}}$ is attributed to electron withdrawing $\mathrm{NO}_{2}$ group. Furthermore, the lowest value of $E_{\text {LUMO }}$ suggests that DAP-1 has greater electron accepting capacity than DAP-2 and DAP-3.
Softness is also an important parameter, which elucidates the adsorption ability of the inhibitor molecules. Higher value of softness and lower value of hardness $(\eta)$ is associated with the strong interaction with metal and the high inhibition efficiency. Table 7 shows that the softness of DAP-1 (1.061) is more than that of DAP-2 (0.970) and DAP-3 (0.869), and the hardness order is as follows: DAP-3 > DAP-2 > DAP-1, which is in accordance with the experimentally obtained inhibition efficiency. The values of fraction of electrons transferred $(\Delta N)$ are presented in Table 7 . It is reported ${ }^{70}$ that electron transfer from an inhibitor to metal takes place easily when the $\Delta N$ value is greater than 0 and less than 3.6. Table 8 reveals that for all the neutral molecules the calculated $\Delta N$ values are positive and less than 3.6, which suggests that the inhibitor molecules have strong tendency to donate electron to the vacant d-orbital of metal.

Fukui index analysis: The Fukuii indices $\mathrm{fk}^{+}$and $\mathrm{fk}^{-}$ predict the most probable atomic sites of the electrophilic and the nucleophilic activities of the inhibitor molecules. ${ }^{35}$ Higher value of $f_{\mathrm{k}}^{+}$suggests acceptance of electron from the metal, while higher value of $f_{\mathrm{k}}^{-}$sites suggests more interaction with the electron deficient species. The calculated Fukui indices are presented in Table 8 . In the case of DAP-1, the most 


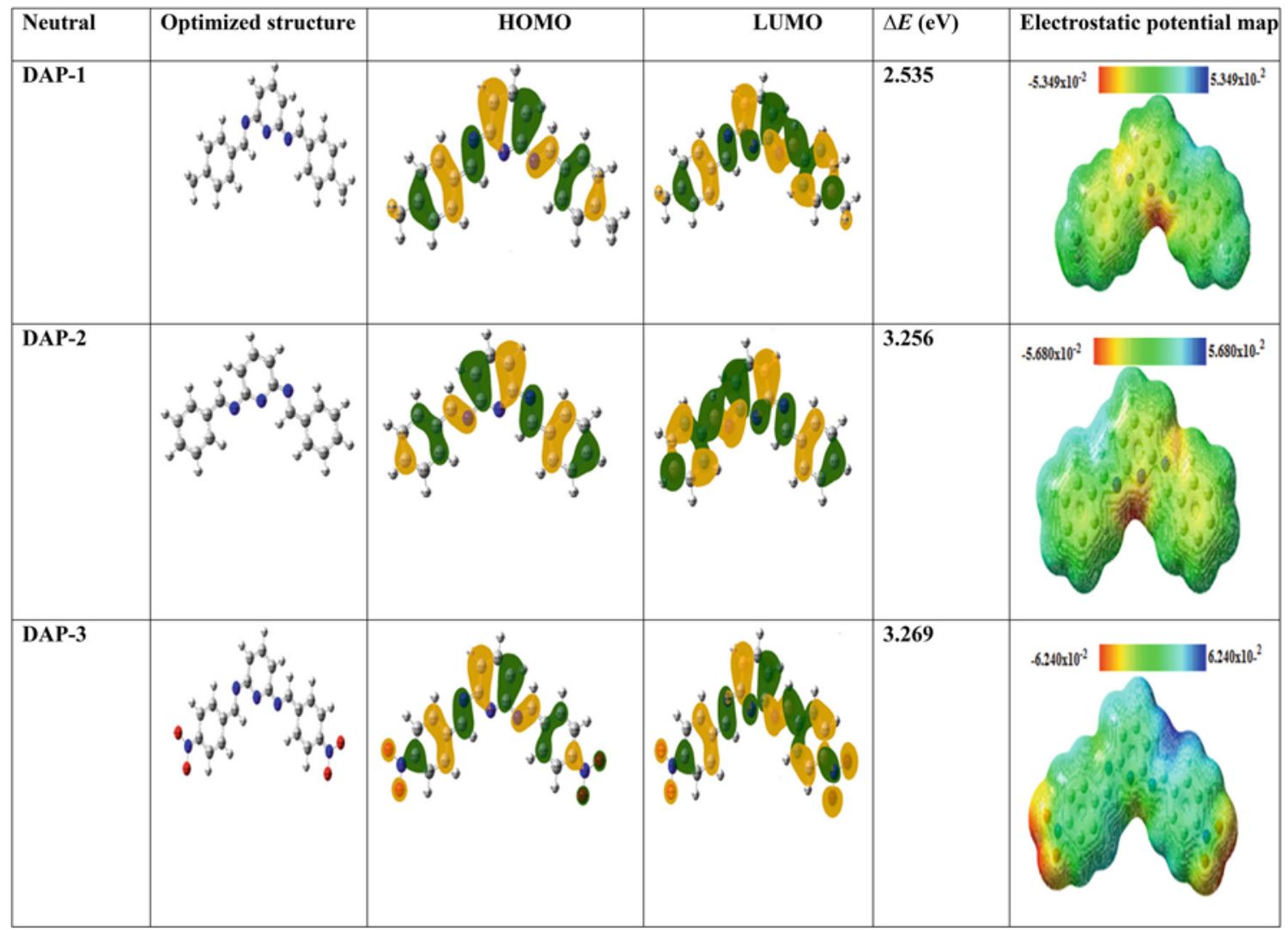

Figure 7. Optimized structures, Frontier molecular orbitals and ESP map for neutral inhibitors molecules. (a) DAP-1, (b) DAP-2, and (c) DAP-3.

Table 6. Mullikan charge on the heteroatoms of neutral DAPs.

\begin{tabular}{|c|c|c|c|c|c|c|c|c|c|}
\hline \multirow[t]{2}{*}{ Inhibitors } & \multicolumn{9}{|c|}{ Mullikan charge on heteroatom's } \\
\hline & $\mathrm{N}_{\mathrm{a}}$ & $\mathrm{N}_{\mathrm{b}}$ & $\mathrm{N}_{\mathrm{c}}$ & $\mathrm{N}_{\mathrm{d}}$ & $\mathrm{O}_{\mathrm{e}}$ & $\mathrm{O}_{\mathrm{f}}$ & $\mathrm{N}_{\mathrm{g}}$ & $\mathrm{O}_{\mathrm{h}}$ & $\mathrm{O}_{\mathrm{i}}$ \\
\hline DAP-1 & -0.59 & -0.53 & -0.489 & - & - & - & - & - & - \\
\hline DAP -2 & -0.58 & -0.52 & -0.486 & - & - & - & - & - & - \\
\hline DAP -3 & -0.58 & -0.51 & -0.475 & -0.232 & -0.405 & -0.409 & -0.233 & -0.410 & -0.411 \\
\hline
\end{tabular}

Table 7. Calculated quantum chemical parameters for DAPs derived from the B3LYP/6-31+G(d,p) method.

\begin{tabular}{lllllll}
\hline Inhibitors & $E_{\text {HOMO } \mathrm{eV}}$ & $E_{\mathrm{LUMO}} \mathrm{eV}$ & $\Delta E \mathrm{eV}$ & $\eta \mathrm{eV}$ & $\mathrm{b}_{\sigma \mathrm{eV}^{-1}}$ & $\Delta N$ \\
\hline Neutral form & & & & & & \\
DAP-1 & -4.216 & -2.331 & 1.885 & 0.942 & 1.061 & 0.820 \\
DAP-2 & -4.223 & -2.163 & 2.060 & 1.030 & 0.970 & 0.789 \\
DAP-3 & -4.312 & -2.012 & 2.30 & 1.150 & 0.869 & 0.720 \\
Protonated form & & & & & \\
DAP-1 & -11.156 & -5.881 & 5.275 & 2.637 & 0.379 & -0.701 \\
DAP-2 & -11.415 & -5.579 & 5.836 & 2.918 & 0.342 & -0.630 \\
DAP-3 & -9.621 & -5.105 & 4.516 & 2.258 & 0.442 & -0.563 \\
\hline
\end{tabular}

susceptible sites for electrophilic attacks and for electron acceptance $\left(f_{\mathrm{k}}^{+}\right)$are: $\mathrm{C}(1), \mathrm{C}(5), \mathrm{C}(9), \mathrm{C}(10), \mathrm{C}(12)$, $\mathrm{C}(14), \mathrm{C}(16), \mathrm{C}(18), \mathrm{C}(20), \mathrm{C}(21)$, and $\mathrm{N}(8)$ and the sites for nucleophilic $\left(f_{\mathrm{k}}^{-}\right)$attack are: $\mathrm{C}(1), \mathrm{C}(2), \mathrm{C}(5)$, $\mathrm{C}(6), \mathrm{N}(7), \mathrm{N}(8)$ and $\mathrm{C}(20)$, respectively. In the case of DAP-2, the active sites for electrophilic attacks are 
Table 8. Calculated Fukui functions for the studied neutral inhibitor molecules

\begin{tabular}{|c|c|c|c|c|c|c|}
\hline Atoms & DAP-1 & DAP-1 & DAP-2 & DAP-2 & DAP-3 & DAP-3 \\
\hline & $\boldsymbol{f}_{k}^{-}$ & $\boldsymbol{f}_{k}^{+}$ & $f_{k}^{-}$ & $\boldsymbol{f}_{k}^{+}$ & $f_{k}^{-}$ & $\boldsymbol{f}_{k}^{+}$ \\
\hline C1 & 0.271 & 0.097 & 0.268 & 0.103 & 0.251 & 0.016 \\
\hline $\mathrm{C} 2$ & 0.048 & 0.029 & 0.062 & 0.019 & 0.062 & -0.0018 \\
\hline N3 & -0.009 & 0.001 & -0.01 & 0.0013 & 0.009 & 0.088 \\
\hline $\mathrm{C} 4$ & 0.035 & 0.007 & 0.043 & 0.013 & 0.043 & 0.022 \\
\hline C5 & 0.277 & 0.131 & 0.276 & 0.124 & 0.266 & 0.007 \\
\hline C6 & 0.042 & 0.004 & -0.038 & -0.008 & -0.037 & 0.008 \\
\hline N7 & 0.05 & 0.032 & 0.038 & 0.022 & 0.034 & 0.022 \\
\hline N8 & 0.06 & -0.017 & 0.054 & 0.077 & 0.05 & 0.08 \\
\hline C9 & 0.054 & 0.138 & 0.066 & 0.093 & 0.067 & 0.03 \\
\hline C10 & 0.034 & 0.137 & 0.042 & 0.171 & 0.043 & 0.162 \\
\hline C11 & 0.016 & -0.0018 & 0.011 & 0.009 & 0.008 & 0.045 \\
\hline C12 & 0.022 & 0.051 & -0.0238 & 0.064 & 0.023 & 0.073 \\
\hline C13 & 0.002 & -0.0034 & -0.0003 & 0 & 0.001 & 0.027 \\
\hline C14 & 0.041 & 0.0745 & 0.039 & 0.022 & 0.039 & 0.117 \\
\hline C15 & -0.002 & -0.0075 & -0.0038 & 0.077 & -0.0041 & 0.014 \\
\hline C16 & 0.023 & 0.0625 & 0.027 & 0.093 & 0.027 & 0.08 \\
\hline $\mathrm{C} 17$ & 0.021 & 0.0016 & 0.013 & 0.171 & 0.01 & 0.007 \\
\hline C18 & 0.03 & 0.059 & 0.032 & 0.0094 & 0.031 & 0.011 \\
\hline C19 & 0.0018 & 0.004 & -0.0012 & 0.064 & -0.0026 & 0.005 \\
\hline $\mathrm{C20}$ & 0.055 & -0.0829 & -0.0523 & 0 & 0.051 & 0.019 \\
\hline $\mathrm{C} 21$ & -0.002 & 0.0829 & -0.0045 & 0.098 & -0.0051 & 0.0018 \\
\hline $\mathrm{C} 22$ & -0.009 & 0.0076 & 0.035 & -0.007 & 0.035 & 0.013 \\
\hline $\mathrm{C} 23$ & -0.01 & 0.0657 & -0.009 & 0.082 & -0.0022 & 0.038 \\
\hline $\mathrm{C} 24$ & 0 & -0.0036 & -0.009 & 0.006 & -0.0029 & 0.006 \\
\hline $\mathbf{N} 23$ & - & - & - & - & 0.0058 & 0.057 \\
\hline N24 & - & - & - & - & 0.01 & 0.037 \\
\hline 025 & - & - & - & - & 0.007 & 0.009 \\
\hline 026 & - & - & - & - & 0.013 & 0.006 \\
\hline $\mathbf{O 2 7}$ & - & - & - & - & -0.0096 & -0.0003 \\
\hline 028 & - & - & - & - & -0.0094 & -0.0001 \\
\hline
\end{tabular}

$\mathrm{C}(1), \mathrm{C}(5), \mathrm{N}(8), \mathrm{C}(9), \mathrm{C}(10), \mathrm{C}(12), \mathrm{C}(15), \mathrm{C}(16)$, $C(17), C(19), C(21)$ and $C(23)$ atoms while, the favorable sites for nucleophilic attack are C(1), C(2), C(4), $\mathrm{C}(5), \mathrm{C}(10), \mathrm{C}(14), \mathrm{C}(20)$ and $\mathrm{N}(8)$ atoms. Likewise, for DAP-3, the sites for electron acceptance are $\mathrm{N}(3)$, $\mathrm{N}(8), \mathrm{C}(10), \mathrm{C}(12), \mathrm{C}(14), \mathrm{C}(16), \mathrm{C}(1), \mathrm{C}(23)$ and $\mathrm{N}(23)$ atoms whereas, $\mathrm{C}(1), \mathrm{C}(2), \mathrm{N}(7), \mathrm{N}(8), \mathrm{C}(9)$, and $\mathrm{C}(20)$, $\mathrm{O}(26), \mathrm{O}(27), \mathrm{O}(28)$ are the electron donating atoms.

The analysis of Fukuii indices reveals that 2,6diaminopyridine ring along with the phenyl ring are the reactive sites are more responsible for donoracceptor interactions and thus facilitate the adsorption of inhibitors over the metallic surface. The atomic positions DAPs are given in the Supplementary Information: Tables S1-S3 for DAP-1 (Neutral, Cation, Anion), Tables S4-S6 for DAP-2 (Neutral, Cation, Anion) and Tables S7-S9 for DAP-3 (Neutral, Cation, Anion).

3.5b Quantum chemical calculations of protonated inhibitor molecules: The optimized structures, HOMO and LUMO distributions are shown in Figure 8. The heteroatom having the most negative value of Mullikan charge is likely to undergo protonation easily. From the inspection of Table 8, it can be observed that the energy gap between $E_{\mathrm{HOMO}}$ and $E_{\mathrm{LUMO}}$ is less as compared to the neutral molecules after the protonation. Table 8 reveals that all the calculated $\Delta N$ values are negative, which means that the electron donation from inhibitor molecules to the metal surface is not possible. It is also noted that $E_{\mathrm{LUMO}}$ values of protonated inhibitors shift towards more negative side as compared to the neutral molecules, which suggests that the protonated inhibitors have higher electron accepting capability compared to the neutral molecules. Thus, in protonated molecules the bond formation between inhibitor and metal takes place by the acceptance of electrons by inhibitor molecules from the metal surface.

3.5c Molecular electrostatic potential: The color region for the electrophilic and the nucleophilic attack to know the reactivity of the inhibitors molecule are studied using molecular electrostatic potential (MEP). ${ }^{65}$ The 


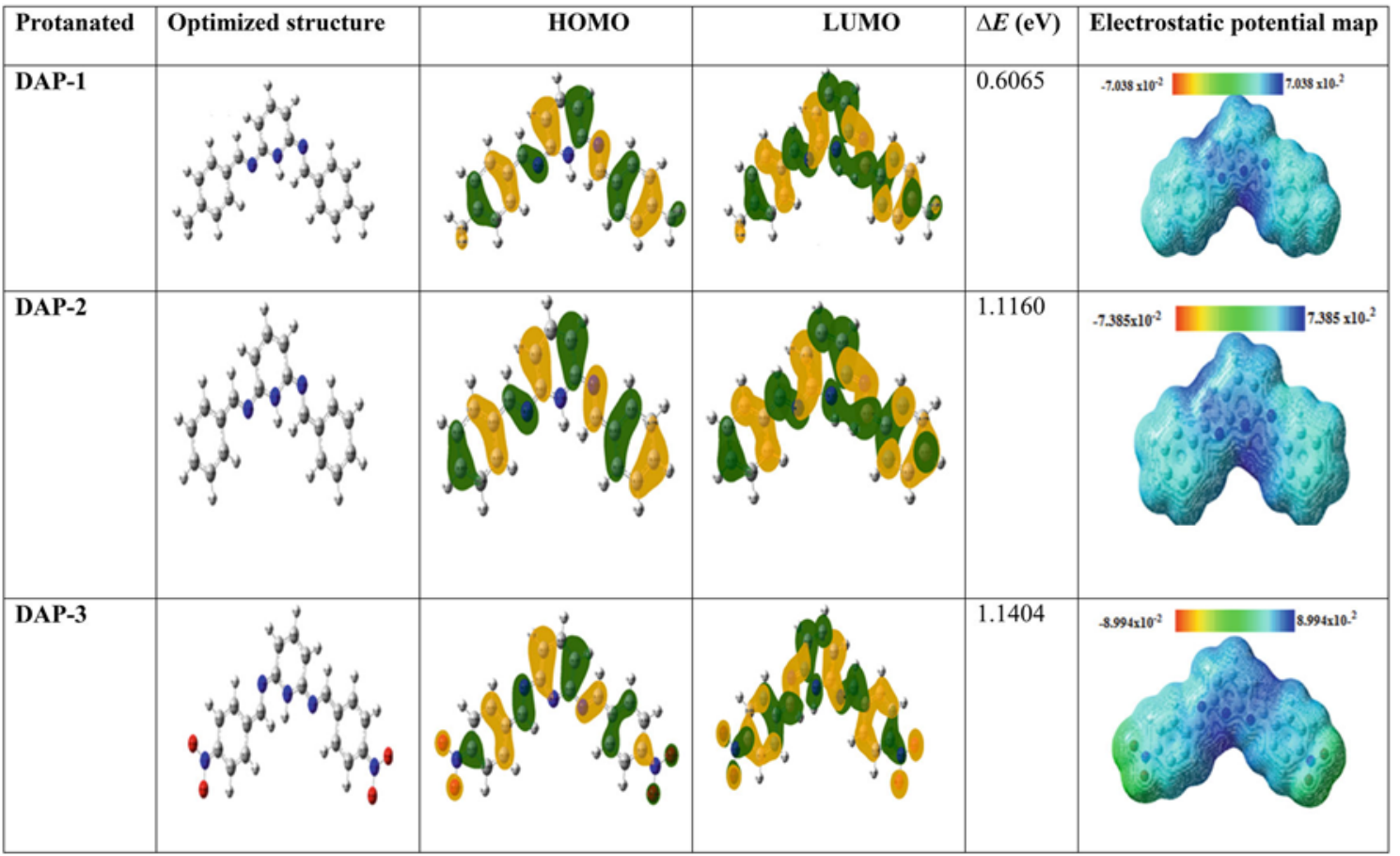

Figure 8. Optimized structure, Frontier molecular orbitals and ESP maps for protonated inhibitors molecules. (a) DAP-1; (b) DAP-2; (c) DAP-3.

MEP map of the inhibitors molecule is calculated by the B3LYP/6-31G(d, p) for the neutral and the protonated inhibitors molecules and are shown in the Figures 7 and 8 , respectively. In the MEP map, the color regions lie in the order of red, green and blue. The color region from red to green is for the nucleophilic attack, and the color region from green to blue is for the electrophilic attack. For the neutral molecules, the color region of MEP lies in between red and green, which are more susceptible to the electrophilic attack. In the MEP map of neutral inhibitors, the most negative potential (red color) are around the N3, N7 and N8 atoms of the diaminopyridine ring. The MEP map for DAP-3 has larger color range due to the $\mathrm{NO}_{2}$ group attached on both sides than the other two inhibitors. From the MEP map of protonated DAP-1, DAP-2 and DAP-3, it can be observed that the whole molecule is ready for nucleophilic attack. The nitrogen atoms (N3, N7 and N8) of the diaminopyridine ring are having the most positive potential (blue color). But in the case of DAP-3, it has both nucleophilic and electrophilic regions due to $\mathrm{NO}_{2}$ groups on both sides of the ring. The color range for the protonated species is larger than that of the neutral species, which is in accordance with the experimental results.

\subsection{Monte Carlo simulations}

The interaction between the inhibitor molecule and metal surface was studied by Monte Carlo simulations. ${ }^{66}$
The adsorption behavior of inhibitor molecules over the metal surface is shown in Figure 9. It is clearly seen that the orientation of the studied inhibitor molecule lies flat on the metal surface. The corresponding values for the outputs and descriptors are listed in Table 9. The parameters include the total energy of the substrateadsorbate configuration, which is defined as the sum of the energies of the adsorbate components, the rigid adsorption energy, and the deformation energy. The substrate energy (i.e., Fe (110) surface) is taken as zero. Moreover, adsorption energy reports the energy released (or required) when the relaxed adsorbate component was adsorbed on the substrate. The adsorption energy is defined as the sum of the rigid adsorption energy and the deformation energy for the adsorbate component. The rigid adsorption energy reports the energy released (or required) when the unrelaxed adsorbate component (before the geometry optimization step) was adsorbed on the substrate. The deformation energy reports the energy released when the adsorbed adsorbate component was relaxed on the substrate surface. Finally, $(\mathrm{dEad} / \mathrm{dNi})$ reports the energy of substrate-adsorbate configurations where one of the adsorbate components has been removed.

The large negative value for adsorption energies in Table 9 suggest that the inhibitor molecule strongly adsorbs onto the $\mathrm{Fe}$ (110) surface. ${ }^{67-69}$ The maximum negative value of adsorption energy for DAP-1 $(-2530.79 \mathrm{~kJ} / \mathrm{mol})$ suggest that DAP-1 more strongly 


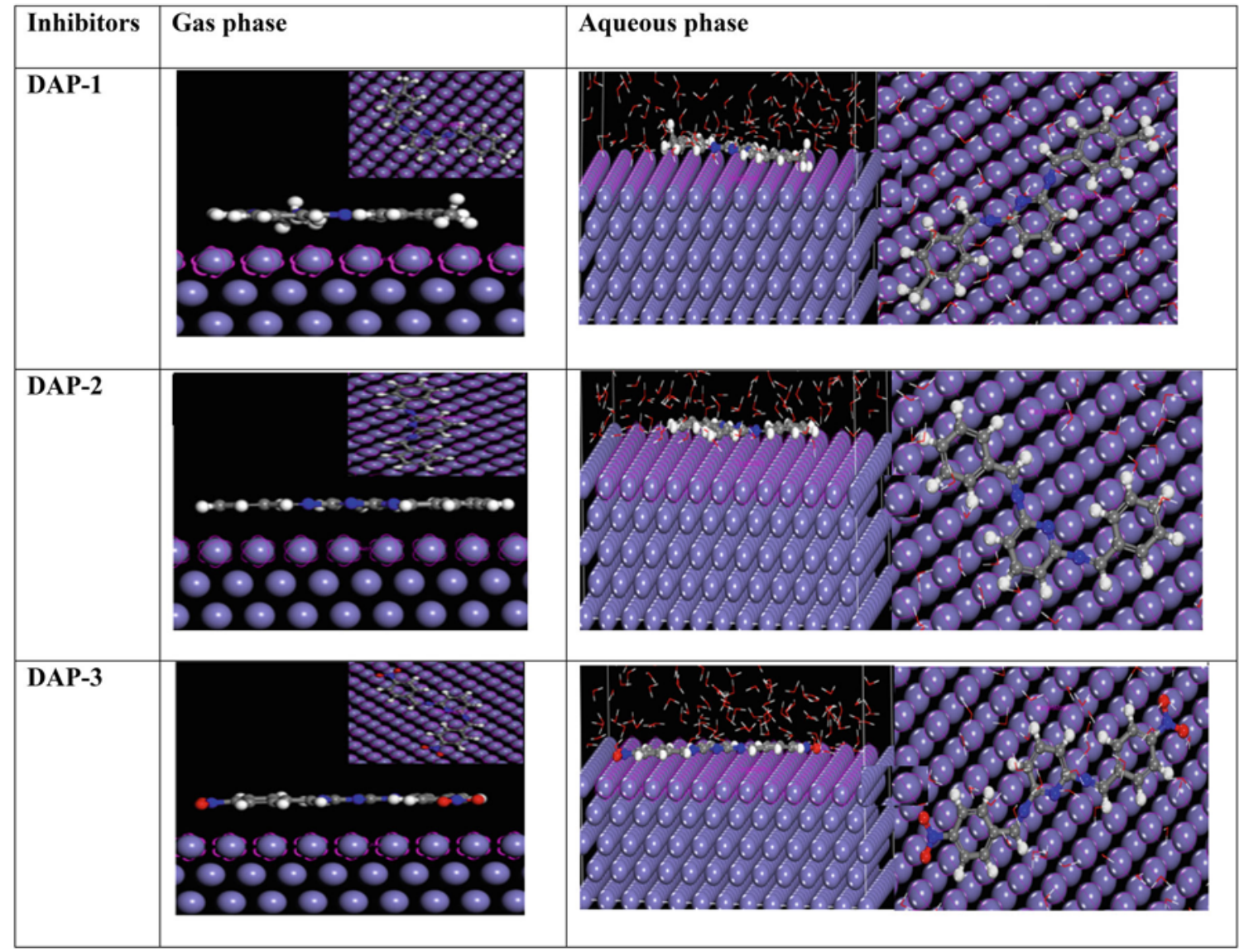

Figure 9. Side views and top views of the most stable configurations for adsorption of, (a) DAP-1, (b) DAP-2, and (c) DAP-3 on Fe (110) surface calculated using Monte Carlo simulations in the gas phase and aqueous phase.

Table 9. Interaction energies between the inhibitors and Fe (110) surface $(\mathrm{kJ} / \mathrm{mol})$

\begin{tabular}{lcccccc}
\hline Inhibitors & $\begin{array}{c}\text { (Total energy) } \\
\mathbf{k J} / \mathbf{m o l}\end{array}$ & $\begin{array}{c}\text { Adsorption } \\
\text { Energy kJ/mol }\end{array}$ & $\begin{array}{c}\text { Rigid adsorption } \\
\text { Energy }\end{array}$ & $\begin{array}{c}\text { Deformation } \\
\text { energy }\end{array}$ & $\begin{array}{c}\text { dEad/dNi: } \\
\text { Inhibitor }\end{array}$ & $\begin{array}{c}\text { dEad/dNi : } \\
\mathbf{H}_{2} \mathbf{O}\end{array}$ \\
\hline (gas phase) & & & & & & \\
DAP -1 & -1030.8 & -2530.79 & -794.13 & -1744.30 & -2530.79 & - \\
DAP-2 & -860.78 & -808.20 & -786.48 & 0.7238 & -808.20 & - \\
DAP-3 & -767.88 & -691.93 & -692.66 & -14.07 & -691.39 & - \\
(aqueous phase) & & & & & \\
DAP -1 & -6325.20 & -6082.86 & -6324.36 & 241.50 & -846.42 & -24.01 \\
DAP-2 & -5921.07 & -5745.38 & -5988.39 & 243.00 & -755.50 & -28.91 \\
DAP-3 & -5965.29 & -5989.77 & -6249.34 & 259.53 & -929.14 & -44.22 \\
\hline
\end{tabular}

adsorbs on the metal surface than DAP-2 and DAP3 (-808.206, -691.397 in $\mathrm{kJ} / \mathrm{mol}$, respectively). This follows the order of the inhibition efficiency obtained in the experiments. The order of the rigid adsorption energy is also according to the experimental results which are as follows: $-794.1315,-786.4832,692.6653$ $\mathrm{kJ} /$ mol for DAP-1, DAP-2, DAP-3, respectively. In order to get the real corrosive environment, it is necessary to conduct the MC simulation in the presence of water. Figure 9 shows the inhibitor (DAP-1, DAP-2, DAP3 ) configuration in the aqueous phase. Table 9 reveals the adsorption energy values in the aqueous phase for the studied inhibitors, DAP-1, DAP-2 and DAP-3. It is generally noticed that the metal-inhibitor interaction is depicted by the adsorption mechanism. High negative adsorption energy values indicate the more stable and 
stronger adsorption. On inspection of Table 9, we see that all the calculated values like total energies, adsorption energies, rigid adsorption energies and deformation energies are very high in the aqueous phase than in the gas phase. This proves that the inhibitor is stable in the aqueous phase and strongly binds to the metal surface. However, there is a change in the regular trends in the Total Energy value, Adsorption Energy value, Rigid adsorption Energy value, and the (dEad/dNi) Inhibitor value of DAP-2 and DAP-3, in the aqueous phase. It does not follow the experimental result. DAP-3 shows higher energies than DAP-2; this is because of the presence of excess oxygen atoms in the $\mathrm{NO}_{2}$ group which can bond strongly with water in a hydrogen bonding. $(\mathrm{O}-\mathrm{H})$. This increases the interaction of the inhibitor molecule with Fe surface. In the gas phase, such hydrogen bonding interaction is not present, therefore the adsorption of DAP-2 is greater than DAP-3. This shows that in aqueous phase, apart from adsorption of the inhibitor on the metal surface, many processes such as hydrogen bonding, protonation of inhibitor molecules in acid solution, $\mathrm{pH}$ of the solution, etc., can lead to a discrepancy in simulation results. From the Table 9, (dEad/dNi) energy of water from the metal surface gives the information about the ease of water removal from the metal surface, which can protect the metal surface from the corrosive aqueous environment.

\section{Conclusions}

All the three tested Schiff base DAPs are good corrosion inhibitors for mild steel in $1 \mathrm{M} \mathrm{HCl}$. Among the three DAPs, DAP-1 having methyl substituent exhibited highest inhibition efficiency of $98.58 \%$ at $40 \mathrm{mgL}^{-1}$. DAPs were found to inhibit corrosion by adsorption mechanism which follows Langmuir adsorption isotherm. The formation of a protective film was confirmed by SEM and AFM. PDP study revealed that all three DAPs act as mixed-type corrosion inhibitors. The high value of polarization resistance $(R \mathrm{p})$ obtained from EIS data further confirmed the effectiveness of the studied corrosion inhibitors. The inhibition efficiency (IE) predicted from theoretical data such as, $E_{\mathrm{HOMO}}, E_{\mathrm{LUMO}}, \Delta \mathrm{E}$ obtained by DFT approach, was very well-correlated with experimentally obtained IE. The MC simulation results follows the order: DAP-1 > DAP-2 $>$ DAP-3 in both aqueous and gas phases, which is in accordance with the experimental IE. The IE ranking for the studied inhibitors is as follows: DAP-1 > DAP-2 > DAP-3. The highest inhibition efficiency of DAP-1 was attributed to its parallel adsorption on the metal surface.

\section{Supplementary Information (SI)}

Figures S1-S3 and Tables S1-S9 are available as Supplementary Information at www.ias.ac.in/chemsci.

\section{Acknowledgements}

PD gratefully acknowledges the financial support of the Ministry of Human Resources and Development (MHRD), New Delhi for providing the Senior Research Fellowship.

\section{References}

1. Hosseini M G, Ehteshamzadeh M and Shahrabi T 2007 Protection of mild steel corrosion with Schiff bases in $0.5 \mathrm{M} \mathrm{H}_{2} \mathrm{SO}_{4}$ solution Electrochim. Acta $\mathbf{5 2} 3680$

2. Behpour M, Ghoreishi S M, Niasar AG, Soltani N and Niasari M S 2009 The inhibition of mild steel corrosion in hydrochloric acid media by two Schiff base compounds J. Mater. Sci. 442444

3. Fan H B, Fu C Y, Wang H L, Guo X P and Zheng J S 2002 Inhibition of corrosion of mild steel by sodium n,n-diethyl dithiocarbamate in hydrochloric acid solution Brit. Corros. J. 37122

4. Bose D, Banerjee J, Rahaman S K H, Mostafa G, Fun H K, Bailey W R D, Zaworotko M J and Ghosh B K 2004 Polymeric end-to-end bibridged cadmium(II)thiocyanates containing monodentate and bidentate $\mathrm{N}$-donor organic blockers: supramolecularsynthons based on $\pi-\pi$ and/or C-H $\cdots \pi$ interactions Polyhedron 232045

5. Abd El-Maksoud S A 2008 The Effect of Organic Compounds on the Electrochemical Behaviour of Steel in Acidic Media A review Int. J. Electrochem. Sci. 3528

6. Ansari K R, Quraishi M A and Singh A 2015 Pyridine derivatives as corrosion inhibitors for N80 steel in 15\% $\mathrm{HCl}$ : Electrochemical, surface and quantum chemical studies Measurement $\mathbf{7 6} 136$

7. Douadi T, Hamani H, Chafaa $S$ and Noaim M A 2015 Corrosion inhibition of mild steel by two new Sheterocyclic compounds in $1 \mathrm{M} \mathrm{HCl}$ : Experimental and computational study Corros. Sci. 9421

8. Zarrok H, Oudda H, Zarrouk A, Salghi R, Hammouti B and Bouachrine M 2011 Weight Loss Measurement and Theoretical Study of New Pyridazine Compound as Corrosion Inhibitor for C38 Steel in Hydrochloric Acid Solution D. Pharma Chem. 3576

9. Popova A, Christov M, Raicheva S and Sokolova E 2004 Adsorption andinhibitive properties of benzimidazole derivatives in acid mildsteel corrosion Corros. Sci. 46 1333

10. Bentiss F, Lebrini M, Vezin H, Chai F, Traisne $M$ and Lagrenée M 2009 Enhanced corrosion resistance of carbon steel in normal sulfuric acid medium by some macrocyclic polyether compounds containing a 1,3,4thiadiazole moiety AC impedance and computational studies Corros. Sci. $\mathbf{5 1} 2165$

11. Pardavé P M, Romo R M, Hernández H H, Quijano M A A, Likhanova N V, Uruchurtu J and Juárez-García J M 2012 Influence of the alkyl chain length of 2 amino 5 alkyl 1,3,4 thiadiazole compounds on the corrosion 
inhibition of steel immersed in sulfuric acid solutions Corros. Sci. 54231

12. Obot I B, Obi-Egbedi N O and Umoren S A 2009 Ginseng root: a new efficient and effective ecofriendly corrosion inhibitor for aluminum alloy of type AA 1060 in hydrochloric acid solution Int. J. Electrochem. Sci. 4 863

13. Quraishi M A and Sardar R 2003 Hector bases-a new class of heterocyclic corrosion inhibitors for mild steel in acid solutions J. Appl. Electrochem. Soc. 331163

14. Khaled K F 2010 Experimental and molecular dynamics study on the inhibition performance of some nitrogen containing compounds for iron corrosion Mater. Chem. Phys. 124760

15. Nataraja S E, Venkatesha T V, Tandon H C and Shylesha B S 2011 Quantum chemical and experimental characterization of the effect of ziprasidone on the corrosion inhibition of steel in acid media Corros. Sci. 534109

16. Silva C M, Silva D N, Modolo L V, Alves R B, Resende M A, Martins C V B and Fatima A 2011 Schiff bases: A short review of their antimicrobial activities J. Adv. Res. 21

17. Silkul P, Ozkınal S, OztürkZ, Asan A and Köse A 2016 Synthesis of novel Schiff Bases containing acryloyl moiety and the investigation of spectroscopic and electrochemical properties J. Mol. Struct. 111672

18. Small B L, Brookhart M and Bennett A M A 1998 Highly Active Iron and Cobalt Catalysts for the Polymerization of Ethylene J. Am. Chem. Soc. 1204049

19. Ulusoy M, Birel O, Sahin O, Buyukgungor O and Cetinkya B 2012 Structural, spectral, electrochemical and catalytic reactivity studies of a series of $\mathrm{N}_{2} \mathrm{O}_{2}$ chelated palladium(II) complexes Polyhedron 38141

20. Negm N A, Badr E, Aiad I A, Zaki M F and Said M M 2012 Investigation the inhibitory action of novel diquaternary Schiff dibases on the acid dissolution of carbon steel in 1M hydrochloric acid solution Corros. Sci. 6577

21. Sorkhabi H A, Shaabani B and Seifzadeh D 2016 Effect of some pyrimidinic Shciff bases on the corrosion of mild steel in hydrochloric acid solution Electrochim. Acta $\mathbf{5 0}$ 3446

22. Yan Ji, Xu Bin, Gong W, Zhang X, Jin X, Ning W, Meng Y, Yang W and Chen Y 2016 Corrosion inhibition of a new Schiff base derivative with two pyridine rings on Q235 mild steel in 1.0M HCl J. Tai. Inst. Chem. E 66

23. Hegazy M A 2009 A novel Schiff base-based cationic gemini surfactants: Synthesis and effect on corrosion inhibition of carbon steel in hydrochloric acid solution Corros. Sci. 512610

24. Singh G S and Mmolotsi B J 2005 Synthesis of 2azetidinones from 2-diazo-1, 2-diarylethanones and $\mathrm{N}$ (2-thienylidene)imines as possible antimicrobial agents Il Farmaco 60727

25. Navarro G, Perez de Vega M J, Garcia-Lopez M T, Andre I G, Snoeck R, Clercq E, Balzarini De and Muniz R G 2005 From 1-acyl-beta-lactam human cytomegalovirus protease inhibitors to 1-benzyloxycarbonylazetidines with improved antiviral activity. A straightforward approach to convert covalent to noncovalent inhibitors J. Med. Chem. 482612

26. Cheng Q, Kiyota H, Yamaguchi M, Horiguchi T and Oritani T 2003 Synthesis and biological evaluation of 4-deacetoxy-1,7-dideoxyazetidine paclitaxel analogue Bioorg. Med. Chem. Lett. 131075

27. Murad K, Deeb A and Kandil F 2014 Synthesis, Characterisation of some 2-azetidinonederivatives from 2,6diaminopyridine and evaluation of their antimicrobial activity Int. J. Chem. Tech. Res. 73762

28. ASTM G 31-72 1990 (American Society for Testing and Materials: Philadelphia PA)

29. Lagrenee M, Mernari B, Bouanis M, Traisnel M and Bentiss F 2002 Study of the mechanism and inhibiting efficiency of 3,5-bis(4-methylthiophenyl)-4H-1,2,4-triazole on mild steel corrosion in acidic media Corros. Sci. 44 573

30. Becke A D 1993 Density-functional thermochemistry. III. The role of exact exchange J. Chem. Phys. 98 5648

31. Becke A D 1998 Density-functional exchange-energy approximation with correct asymptotic behavior Phys. Rev. A 383098

32. Palaniappan N, Chowhan L R, Jothi S, Bosco I G and Cole I S 2017 Corrosion inhibition on mild steel by phosphonium salts in $1 \mathrm{M} \mathrm{HNO}_{3}$ aqueous medium Surf. Interfaces $\mathbf{6} 237$

33. Olasunkanmi L O, Obot I B, Kabanda M M and Ebenso E E 2015 Some Quinoxalin-6-yl Derivatives as Corrosion Inhibitors for Mild Steel in Hydrochloric Acid: Experimental and Theoretical Studies J. Phys. Chem. C 119 16004

34. Obot I B, Kaya S, Kaya C and Tüzün B 2016 Theoretical evaluation of triazine derivatives as steel corrosion inhibitors: DFT and Monte Carlo simulation approaches Res. Chem. Intermed. 424963

35. Martinez S 2003 Inhibitory mechanism of mimosa tannin using molecular modeling and substitutional adsorption isotherms Mater. Chem. Phys. 7797

36. Obot I B and Gasem Z M 2014 Theoretical evaluation of corrosion inhibition performance of some pyrazine derivatives Corros. Sci. 83359

37. Obot I B, Kaya S, Kaya C and Tüzün, B 2016 Density Functional Theory (DFT) modeling and Monte Carlo simulation assessment of inhibition performance of some carbohydrazide Schiff bases for steel corrosion Physica E 8082

38. Kumar A M, Babu R S, Obot I B and Gasem Z M 2015 Fabrication of nitrogen doped graphene oxide coatings: experimental and theoretical approach for surface protection RSC Adv. 519264

39. Dohare P, Chauhan D S, Hammouti B and Quraishi M A 2017 Experimental and DFT Investigation on the Corrosion Inhibition Behavior of Expired Drug Lumerax on Mild Steel in Hydrochloric Acid Anal. Bioanal. Electrochem. 9762

40. Wadhwani P M, Ladha D G, Panchal V K and Shah N K 2015 Enhanced Corrosion Inhibitive Effect of Pmethoxybenzylidene-4,4-dimorpholine Assembled on Nickel Oxide Nanoparticles for Mild Steel in Acid Medium RSC Adv. 57098

41. Dohare P, Ansari K R, Quraishi M A and Obot I B 2017 Pyranpyrazole derivatives as novel corrosion inhibitors for mild steel useful for industrial pickling process: Experimental and Quantum Chemical study J. Ind. Eng. Chem. 52197 
42. Guan N M, Xueming L and L Fei 2004 Synergistic inhibition between o-phenanthroline and chloride ion on cold rolled steel corrosion in phosphoric acid Mater. Chem. Phys. 8659

43. Sahin M, Bilgic S and Yilmaz H 2002 The inhibition effects of some cyclic nitrogen compounds on the corrosion of the steel in $\mathrm{NaCl}$ medium Appl. Surf. Sci. 195 1

44. Larabi L, Harek Y, Benali O and Ghalem S 2005 Hydrazide derivatives as corrosion inhibitors for mild steel in 1M HCl Prog. Org. Coat. 54256

45. Ghareba S and Omanovic S 2010 Interaction of 12aminododecanoic acid with a carbon steel surface: Towards the development of 'green' corrosion inhibitors Corros. Sci. 522104

46. Solmaz R 2014 Investigation of corrosion inhibition mechanism and stability of Vitamin B1 on mild steel in $0.5 \mathrm{M} \mathrm{HCl}$ solution Corros. Sci. 8175

47. Solmaz R 2014 Investigation of adsorption and corrosion inhibition of mild steel in hydrochloric acid solution by 5-(4-Dimethylaminobenzylidene)rhodanine Corros. Sci. 79169

48. Hu K, Zhuang J, Zheng C, Ma Z, Yan L, Gu H, Zeng $X$ and Ding J 2016 Effect of novel cytosine-1-alanine derivative based corrosion inhibitor on steel surface in acidic solution J. Mol. Liq. 222109

49. John S, Kuruvilla M and Joseph A 2013 Adsorption and Inhibition Effect of Methyl Carbamate on Copper Metal in $1 \mathrm{NHNO}_{3}$ : An Experimental and Theoretical Study RSC Adv. 38929

50. Daoud D T, Douadi T, Issaadi S and Chafaa S 2014 Adsorption and corrosion inhibition of new synthesized thiophene Schiff base on mild steel X52 in $\mathrm{HCl}$ and $\mathrm{H}_{2} \mathrm{SO}_{4}$ solutions Corros. Sci. 7950

51. Ehsani A, Mahjani M G, Moshrefi R, Mostaanzadeha $\mathrm{H}$ and Shayehb J S 2014 Electrochemical and DFT Study on the Inhibition of 316L Stainless Steel Corrosion in Acidic Medium by 1-(4-nitrophenyl)- 5-amino-1Htetrazole RSC Adv. 420031

52. Ehteshamzadeh M, Jafari A H, Naderia E and Hosseini M G 2009 Effect of carbon steel microstructures and molecular structure of two new Schiff base compounds on inhibition performance in $1 \mathrm{M}$ $\mathrm{HCl}$ solution by EIS Mater. Chem. Phys. 113 986

53. Moradi M, Duan J and Du X 2013 Investigation of the effect of 4,5-dichloro-2-n-octyl-4-isothiazolin-3-one inhibition on the corrosion of carbon steel in Bacillus sp. inoculated artificial seawater Corros. Sci. 69 338

54. Tang Y, Zhang F, Huc S, Cao Z, Wu Z and Jing W 2013 Novel benzimidazole derivatives as corrosion inhibitors of mild steel in the acidic media. Part I: Gravimetric, electrochemical, SEM and XPS studies Corros. Sci. 74 271

55. Pearson R G 1988 Absolute Electronegativity and Hardness: Application to Inorganic Chemistry Inorg. Chem. 27734

56. Gomez B, Likhanova N V, Dominguez M A, MartinezPalou R, Vela A and Gazquez J L 2006 Quantum Chemical Study of the Inhibitive Properties of 2-pyridylazoles J. Phys. Chem. B $\mathbf{1 1 0} 8928$
57. Naderi E, Jafari A H, Ehteshamzadeha $\mathrm{M}$ and Hosseini M G 2009 Effect of carbon steel microstructures and molecular structure of two new Schiff base compounds on inhibition performance in $1 \mathrm{M} \mathrm{HCl}$ solution by EIS Mater. Chem. Phys. 115852

58. Quraishi M A, Rafiquee M Z A, Khan S and Saxena N 2007 Corrosion inhibition of aluminium in acid solutions by some imidazoline derivatives J. Appl. Electrochem. 37 1153

59. Umoren S A, Obot I B, Israel A U, Asuquo P O, Solomon M M, Eduok U M and Udoh A P 2014 Inhibition of Mild Steel Corrosion in Acidic Medium using Coconut Coir Dust Extracted from Water and Methanol as Solvents $J$. Ind. Eng. Chem. 203612

60. Yadav D K, Maiti B and Quraishi M A 2010 Electrochemical and quantum chemical studies of 3,4dihydropyrimidin-2(1H)-ones as corrosion inhibitors for mild steel in hydrochloric acid solution Corros. Sci. 52 3586

61. Dutta A, Panja S S, Nandi M M and Sukul D 2015 Effect of optimized structure and electronic properties of some benzimidazole derivatives on corrosion inhibition of mild steel in hydrochloric acid medium: Electrochemical and theoretical studies J. Chem. Sci. 127921

62. Olasunkanmi L O, Kabanda M M and Ebenso E E 2016 Quinoxaline derivatives as corrosion inhibitors for mild steel in hydrochloric acid medium: Electrochemical and quantum chemical studies Phys. E 76109

63. Lu T and Chen F 2012 Quantitative analysis of molecular surface based on improved Marching Tetrahedra algorithm J. Mol. Graphics Modell. 38314

64. Zhang Q B and Hua Y X 2009 Corrosion inhibition of mild steel by alkylimidazolium ionic liquids in hydrochloric acid Electrochim. Acta 541881

65. Zhao P, Liang Q and Li Y 2005 Electrochemical, SEM/EDS and quantum chemical study of phthalocyanines as corrosion inhibitors for mild steel in $1 \mathrm{~mol} / \mathrm{H} \mathrm{HCl}$ Appl. Surf. Sci. 2521596

66. Zeng J P, Zhang J Y and Gong X D 2011 Molecular dynamics simulation of interaction between benzotriazoles and cuprous oxide crystal Compt. Theo. Chem. 963 110

67. Kaya S, Tüzün B, Kaya C and Obot I B 2016 Determination of corrosion inhibition effects of amino acids: Quantum chemical and molecular dynamic simulation study J. Taiwan Inst. Chem. Eng. 58528

68. Obot I B, Umoren S A, Gasem Z M, Suleiman R and El Ali B 2015 Theoretical prediction and electrochemical evaluation of vinylimidazole andallylimidazole as corrosion inhibitors for mild steel in $1 \mathrm{M} \mathrm{HCl} \mathrm{J.} \mathrm{Ind.} \mathrm{Eng.}$ Chem. 211328

69. Ramaganthan B, Gopiraman M, Olasunkanmi L O, Kabanda M M, Yesudass S, Bahadur I, Adekunle A S, Obot I B and Ebenso E E 2015 Synthesized photo cross linking chalcones as novel corrosion inhibitors for mild steel in acidic medium: experimental, quantum chemical and Monte Carlo simulation studies $R S C A d v$. 5 76675

70. Lukovits I, Kalman E. and Zucchi F 2001 Corrosion Inhibitors-Correlation between Electronic Structure and Efficiency Corrosion 57 3. https://doi.org/10.5006/ 1.3290328 